\title{
A TURBULENT TRANSPORT NETWORK MODEL IN MULTIFLUX COUPLED
} WITH TOUGH2

\author{
G. Danko ${ }^{1}$, D. Bahrami ${ }^{1}$, J. Birkholzer ${ }^{2}$
}

${ }^{1}$ Department of Mining Engineering, University of Nevada Reno

${ }^{2}$ Lawrence Berkeley National Laboratory (LBNL) 


\section{$\underline{\text { ABSTRACT }}$}

A new numerical method is described for the fully-iterated, conjugate solution of two discrete sub-models, involving (1) a transport network model for heat, moisture, and air flows in a high-permeability, fluid-filled cavity; and (2) a fractured porous medium. The transport network sub-model is an integrated parameter, Computational Fluid Dynamics (CFD) solver, describing the thermal-hydrologic transport processes in the flow channel system of the cavity with laminar or turbulent flow and convective heat and mass transport, using MULTIFLUX. The porous medium submodel, using TOUGH2, is a solver for the heat and mass transport in the fractured rockmass. The new model solution extends the application fields of TOUGH2 by integrating it with turbulent flow and transport in a discrete flow network system. We present demonstrational results for a nuclear waste repository application at Yucca Mountain with the most realistic model assumptions and input parameters including the geometrical layout of the nuclear spent fuel and waste with variable heat load for the individual containers. The MULTIFLUX and TOUGH2 model elements are fully iterated, applying a programmed reprocessing of the Numerical Transport Code Functionalization (NTCF) model-element in an automated Outside Balance Iteration (OBI) loop. The natural, convective air flow field, as well as the heat and mass transport in a representative emplacement drift during post-closure are explicitly solved in the new model. The results demonstrate that the direction and magnitude of the air circulation patterns and all transport modes are strongly affected by the heat and moisture transport processes in the surrounding rock, justifying the need for a coupled, fully-iterated model solution such as the one presented in the paper. 


\section{INTRODUCTION}

The thermal-hydrologic storage environment in the emplacement drift at the conceptual nuclear waste storage facility at Yucca Mountain has been extensively studied in the past decade with various modeling approaches. A review of the models regarding the coupled in-drift and inrock processes are given in a previous paper [1]. Previous models used various levels of simplifications in capturing the in-drift processes in their thermal-hydrologic interactions to those in the near-field and far-field rockmass. Most of the baseline studies, including those in the License Application (LA), bypassed the difficulties of modeling the air movement and natural convection in the emplacement drift during post-closure period by considering the axial convection as insignificant [2]. Other studies used the concept of effective, equivalent dispersion in the air in axial direction $[3,4]$. The input data for the equivalent dispersion coefficient were provided by a limited-scale, simplified numerical study, assuming a 70-m long emplacement drift segment with assumed boundary conditions [5]. The natural air recirculation field and the resulting convective heat and mass transport were first simulated using MULTIFLUX coupled to TOUGH2 in a previous paper [1]. Some simplifications such as line heat load and a symmetric waste package arrangement with long unheated sections were used. However, the LA design includes a rich variations of localized heat loads in individual waste packages which could be important to the in-drift storage environment. The unheated sections at either end of the emplacement drift were also varied in the LA from previous, symmetrical designs, requiring model refinement. It has been shown before that the unheated drift end sections can significantly affect the in-drift humidity during post-closure [6,7]. Another technical limitation was also applied in the previous work [1] by limiting the number of NTCF model updates. A manual OBI loop was used for obtaining the NTCF model and the process continued only to the $11^{\text {th }}$ iteration. 
This number was found adequate for convergence for an equivalent dispersion in-drift model and was accepted for the in-drift convective model as well $[1,7]$.

The goal in the present paper is to study the LA case with its assumed layout geometry and design specifications with the coupled in-drift and in-rock model. The key elements of the coupled modeling approach are described in a previous publication [1]: (1) the separation of the rock-mass model from the in-drift model; (2) the solution of the rockmass model with TOUGH2 [8] combined with the NTCF technique [9] for generalization; (3) the solution of the internal components of the emplacement drift with an integrated-parameter CFD model; and (4) the recoupling of the separate tasks (2) and (3) iteratively at each time instant and boundary element on the drift wall.

In order to continue the OBI cycles for the convective model, it was necessary to automate the manual process in MULTIFLUX. A computer macro script was written, emulating the manual file-management process and greatly simplifying the necessary user interactions. The new simulations include the convective model results as the ultimate solution to the most recent LA case. Variable heat load along the emplacement drift length from the waste packages with different decay heat characteristics, convective large-eddy, laminar or turbulent air flow, heat and moisture transport were used.

\section{MULTI-SCALE, COUPLED NUMERICAL-COMPUTATIONAL MODEL}

\section{$\underline{\text { The Coupled Model Domain }}$}

The coupled in-drift and in-rock model domains is shown schematically in Figure 1. The dominant, expected flow patterns of air, heat and moisture in axial, as well as transversal directions, are also depicted. A detailed description of the geometry of each domain can be found in previous publications and research reports [7,10]. A new element in the present study is 
that the unheated drift end sections are different in length, following the latest design variations for Yucca Mountain.

\section{Thermal-hydrologic Model of the Rockmass}

The thermal-hydrologic processes in the rockmass are modeled using TOUGH2 according to a three-dimensional configuration by Birkholzer $[3,4]$. The results from the TOUGH2 code are imported into the coupled in-drift and in-rock model using the NTCF coupling technique. The length of the drift is $760 \mathrm{~m}$, with two unheated end sections where no waste is emplaced. The length of the unheated end sections are adjusted to $60 \mathrm{~m}$ and $15 \mathrm{~m}$, according to the latest design variation in the license application [2]. It has been pointed out in previous studies, e.g., by Danko et al. [6,7] that the axial moisture transport and the humidity in the emplacement drift are quite sensitive to the length of the unheated sections. The unheated drift sections are connected to the undisturbed and also unheated rockmass resulting in a strongly three-dimensional temperature and humidity as well as condensation field in and around the drift. Due to the large temperature gradient, a minor modification in the unheated drift length may cause significant differences in the thermal-hydrologic environment.

In the previous studies $[1,7]$, the NTCF model representing the rock-mass was nonlinear, in order to provide an extended range for prediction and to minimize the number of necessary OBI iterations. A complete list of NTCF models with corresponding equations for heat and moisture are given in the Appendix. In the present study with automated OBI cycle, a linear NTCF model-type served better, being faster to process, and having higher numerical stability, as follows:

$$
\begin{aligned}
& q h=q h^{c}+h h \cdot\left(T-T^{c}\right) \\
& q m=q m^{c}+m m \cdot\left(P-P^{c}\right)
\end{aligned}
$$


Where $q h$ and $q m$ are NTCF output heat and moistures fluxes,

$h h$ and $m m$ are NTCF dynamic admittance matrices for heat and moisture,

$T$ is input temperature vector with elements representing values at sampled time instants,

$P$ is input vapor pressure vectors with elements representing values at sampled time instants.

superscript $c$ refers to central boundary conditions.

The $h h$, and $m m$ dynamic admittance matrices are identified based on Eqs (1) and (2) by fitting $q h$ and $q m$ to TOUGH2 data. The NTCF model identification method follows the technique described in Danko [9]. The model for each drift-section perfectly reproduces $q h^{c}$ and $q m^{c}$, the central output fluxes from TOUGH2, for $T=T^{c}$ and $P=P^{c}$, the central input boundary conditions, that are included in the pre-selected set of boundary conditions.

Other $T$ and $P$ input variations can produce outputs from the NTCF model for $q h$ and $q m$ without actually re-running TOUGH2. For the coupled in-rock and in-drift model, 454 driftscale NTCF models are generated from the mountain-scale NTCF models by scaling, following the technique used in Danko et al. [1,7].

\section{CFD Model for Air Flow, Heat, and Moisture Transport in the Emplacement Drift}

The integrated-parameter in-drift CFD model provides the solution of three coupled transport processes:

(1) Momentum transport in the air space, governing the air flow field and barometric pressure distribution;

(2) Energy transport in the emplacement drift, governing the heat flow field and temperature distribution; and

(3) Moisture transport in the emplacement drift, governing the moisture, vapor, and condensate flow fields and the relative humidity distribution. 
The CFD model in MULTIFLUX applies three inter-connected network models for the solution of the coupled transport processes (1) through (3). The network equations are obtained from the governing equations known as the Navier-Stokes equations for viscous fluid flow, the Fourier's equation for heat conduction and convection, and the Fick's equation for mass diffusion and convection. The governing equations as well as their network equation solutions are described in detail in the User's Manual of MULTIFLUX [11]. These governing equations are also recited in the Appendix.

The CFD model domain is similar to that in a previous study $[1,7]$. However, the air flow, heat, and mass transport connections within the emplacement drift are re-configured to include three model cases for investigating the effects of air circulation upon axial heat and moisture transport in the drift during post-closure. In the first, diffusive model case, no air movement is assumed in the axial direction in the drift, and the heat and moisture transports are rendered to the default mechanism of molecular diffusion. In the second, dispersive model case, a thousand times enhancement of the molecular diffusion coefficient is assigned in the axial direction. This treatment is found in the literature [2] for approximating convective effects [2] by dispersion. In the third, convective model case, a true, convective model is applied, explicityl describing the effects of in-drift air circulation.

It must be emphasized that in the integrated-parameter solution of the Navier-Stokes equation the density is treated as a function of the temperature and water vapor content, both variable within the in-drift air space, creating dual buoyancy driving forces. The open air cross section of the emplacement drift in the present model configuration is divided into eight segments, four outside and four inside the drip shields, forming eight longitudinal air flow network lines. The integrated-parameter CFD model for air flow applies 16 velocity components, eight along horizontal lines parallel with the drift axis and eight in transversal, normal direction to the drift 
axis at each drift cross section. The CFD nodes in the airway are arranged along four longitudinal lines outside the drip shields and also four lines inside the drip shields in a halfcross-section of the drift. The velocity components and their positive directions are defined in Figure 2 for the air space inside and outside the drip shields. Along a full drift, $454 \times 16=7264$ velocity components are determined from the integrated-parameter air flow model. The energy and moisture transport equations are discretized and solved numerically and simultaneously along all flow channels. In the drift, $18 \times 454=8172$ nodes are used for the air flow, heat, and the same number of nodes for the moisture transport. Each waste package is represented by two nodes, with one additional node for the gap between neighboring containers in the axial direction. The drift wall is separated from the rock with a $10^{-5} \mathrm{~m}$ thick still air layer representing the rock-air interface, and acting as a coupling layer of insignificant resistance to transport of heat and moisture. The drift wall in each half-cross section is represented by three nodes at the invert, sidewall, and roof. Both the drift wall and the thin coupling layers are represented by 454 nodes each along the three longitudinal lines spanning the drift length at the invert, sidewall, and roof. Half of the drip shields on either side of the symmetry line is integrated into four nodes defining four lines, two on the top and two on the side, each pair separated by the thickness of the drip shields. The air spaces outside and inside the drip shields also include two separate steam transport lines, for superheated steam removal, with 454 nodes along each line. Heat and moisture transport are modeled using heat and moisture transport coefficients at the solid surfaces of the waste package, drift wall, and at each side of the drip shields. Three-dimensional thermal radiation between solid surfaces is also included in the integrated-parameter CFD model.

\section{Coupled In-Rock and In-Drift Model Solution}

The two main model-elements that need coupling are (1) the integrated-parameter CFD model for heat, moisture, and air flow in the drift; and (2) the NTCF surrogate model for the 
rockmass. Figure 3 is a solution flowchart in MULTIFLUX with the CFD and NTCF modules. Coupling between the CFD and NTCF model-elements is made by the Direct Iteration and Successive Approximation Coupler (DISAC) module, performing an Inside Balance Iteration (IBI) cycle. DISAC matches temperature $(T)$ for heat, partial vapor pressure $(P)$ for humidity, $\left(q_{h}\right)$ heat flux, and $\left(q_{m}\right)$ moisture flux at each coupling surface node and time instance during simulation. The coupled simulation result are processed and saved by the DISAC module.

Three iteration loops are used in the IBI cycle to balance the in-rock and in-drift transport processes, starting from the first, most inner loop to the third outer loop:

1. Heat-flow-balance iteration between the NTCF and airway CFD models for each time division.

2. Moisture-flow-balance iteration between the NTCF and airway CFD models for each time division.

3. Natural air flow field calculations in the closed air space of the emplacement drift. For each set of balanced results from iterations 1 and 2, the air flow velocity field is solved based on the new, updated temperature and vapor-pressure distributions. The three iteration loops are executed until no significant change is observed in the results between consecutive iterations. While the CFD model-element is solved within MULTIFLUX, the NTCF model-element is only a surrogate model for the TOUGH2, the independent solver for the transport processes in the rockmass. In high temperature, strongly non-linear applications, the NTCF model parameters must be refreshed during coupling iterations. An outside balance evaluation (OBE) is performed in which the $T$ and $P$ results from the current IBI iteration are compared with previous values, which are $T_{c}$ and $P_{c}$, used for the current NTCF model identification for each time division. If the comparison shows a large difference (e.g., more than 5\% difference in any of the 
input values of the multi-component vectors), the NTCF model is updated with new matrix coefficients, repeating the OBI process with the new $T_{c}=T$ and $P_{c}=P$ vectors as input variables. This OBE condition limits the designated working range of the NTCF model, minimizing potential prediction error. The OBI iteration continues until convergence is achieved.

\section{Model Calculation, Input and Output}

The numerical code, MULTIFLUX version 5.0, is used in the evaluation of the three different in-drift transport model approaches, each utilizing different transport mechanism. The first case, referred to as the "diffusive model," assumes only molecular diffusion in axial direction with no dispersion enhancement. The second case, referred to as the "dispersive model," applies a dispersion coefficient set to 1000 times the air molecular diffusion due to axial convection-enhancement. The third case, referred to as the "convective model," applies the true, coupled convective transport model. Comparison between the three different cases allows for evaluating the significance of coupling the in-drift and in-rock model domains (i.e., coupling MULTIFLUX and TOUGH2) upon the results. The ultimate coupled solution, in which the natural air flow field in the drift caused by dual-buoyancy forces, is explicitly and iteratively solved with MULTIFLUX and TOUGH2.

The driving force of the entire coupled thermal-hydrologic transport problem is the heat generated by the spent nuclear fuel and waste emplaced in the drift. Waste packages are modeled as individual heat sources according to a eight-package, repeated sequence published in previous reports [10]. The initial, line-averaged heat load at the time of emplacement is 1.45 $\mathrm{kW} / \mathrm{m}$. The heat load distribution along the drift length and with time is shown in Figure 4 . The large variation between high and low heat dissipation causes a corresponding variation in 
temperature around them and a ruggedness in the temperature and humidity variations along the drift length.

\section{Discussion of the Model Simulation Results}

The in-drift air velocity fields are presented first from the convective model. The velocity fields are the results of the complete thermal-hydrologic simulation in the drift air space, coupled to the thermal-hydrologic simulation in the rockmass. Therefore, these results implicitly include the temperature and humidity distributions. Figure 5 shows the axial air velocity variation along the drift length, outside the drip shields, at six selected time instants. Figure 6 depicts the results for the air space inside the drip shields. We present the three-dimensional velocity field in the form of dominant air circulation loops in axial and transversal directions. The positive velocity identifies air flow direction from the entrance toward the exit end. The four air lines in each air space (inside or outside the drip shields) are grouped in two lines which form a closed circulation loop. For example, if flows along three air lines go in one direction, they are averaged into one line. The results show large and small axial air circulation loops. The large loops are longdistance events, while the small ones are formed over a short axial distance. As shown in Figure 5, no small air flow loops are present in the air space outside the drip shields from year 75 . Results for the air space inside the drip shields in Figure 6 show more small-distance, axial circulation loops. This circulation behavior is consistent with expectations: a larger air space outside the drip shields has lower axial flow resistance and a correspondingly more uniform flow pattern under small driving force changes along the drift length.

The long, axial circulation loops provide direct, convective moisture transport between the hot, middle drift section and the unheated end sections. The formation of robust axial air flow loops and their effects on axial heat and moisture transport are important, new discoveries from the present model results, contradicting the perceived consensus about the insignificance of axial 
heat and moisture transport in the emplacement drift during post-closure at Yucca Mountain. The large-eddy flow structure, apparent from the MULTIFLUX results, represents a strong axial heat and moisture transports. Consequently, conditions will be generally drier in most of the drift sections where waste is emplaced, and wetter at the end sections where no waste is emplaced.

The transversal air velocity components $v_{1}{ }^{\mathrm{v}}$ through $v_{8}^{\mathrm{v}}$, shown in Figure 2 are averaged in each vertical cross section in order to find a mean vertical circulation velocity. The vertical circulation velocity variations along the drift length at selected time periods are shown in Figures 7 and 8 for the air space outside and inside the drip shields, respectively. The variation in the velocity in the transversal circulation loops in the vertical cross-sections is strong along the drift length. Even the direction of the circulation reverses along the drift length perhaps multiple times, as indicated by the positive and negative signs of the averaged velocity distributions. The ruggedness of the velocity curves is caused by a rich variation of flow driving forces due to temperature and humidity variations, and further enhanced by sharply varying cross sections in the air-filled gaps between the individual waste packages.

The boundary conditions on the full drift surface with the strong variations of temperature and humidity in the MULTIFLUX model are fully coupled and balanced with the in-rock TOUGH2 model. The natural driving force for the horizontal and transversal air circulations come from air density variations due to temperature and humidity changes. The change in the rotational direction of the transversal velocities along the drift length indicates that the air density change due to humidity variation becomes dominant over the change in air density due to temperature variation at the cold and humid drift sections. This fact agrees with what common sense would dictate. In a hot drift section, the transversal air circulation is expected to be dominantly temperature driven, causing upward air flow in the drift center. In a cold drift end 
section with high relative humidity, the effect of vapor content on the air density may overwhelm that of temperature. More humid and lighter air may rise over the drift wall and descend farther from the drift wall, reversing the transversal circulation loop direction.

Figure 9 shows the axial distribution of the average drift wall temperature for the side walls and the drift crown outside the drip shields. The results show that prior to year 500, the diffusive and dispersive models are similar while they are very different from the convective models. Large differences are seen in the temperatures variations near the edges of the heated section for all time intervals. Figure 10 shows the drift wall temperatures inside the drip shields, i.e., on the footwall of the invert. The temperature level as well as the axial temperature variation are nearly identical to those for the drift wall outside the drip shields. An asymmetry in the temperature field between the two drift ends is apparent, reaching a maximum of $12{ }^{\circ} \mathrm{C}$ at Year 75 . The difference in temperature is caused by the different lengths of the unheated sections, i.e., $60 \mathrm{~m}$ and $15 \mathrm{~m}$, respectively.

Figure 11 shows the axial distribution of the average relative humidity on the drift wall outside the drip shields. The results show that the hot region is generally drier from the convective model than from the dispersive and diffusive models due to more intensive axial moisture transport. Figure 12 depicts the relative humidity distributions on the invert of the drift wall inside the drip shields, showing generally higher values than those for the drift wall outside the drip shields. This finding is somewhat unexpected, since the temperature level is definitely not lower than in the outside drip shields area. The explanation must come from the fact that the vapor flux from the rock wall is higher in the footwall area than from the crown or the side walls of the drift. The vapor trapped under the drip shields causes a higher humidity concentration in the air space around the waste packages than the one in the drift outside the drip shields. This is another element of the somewhat unfavorable impacts of the drip shields upon the near-waste 
package thermal-hydrologic environment: they cause higher temperature as well as humidity. The asymmetry in the drift wall relative humidity inside the drip shields between the two ends of the emplacement section is about $12 \%$ observed at Year 51.

Figures 13 and 14 show the condensation distributions for the convective, diffusive and dispersive models outside and inside the drip shields, respectively. Figure 15 shows the summary of condensation distributions, depicting the sum of total condensation along the drift length as a function of time for the three different models. Figure 15 also gives the total vapor inflow into the drift from the near-field rockmass. As shown, for the first few hundred years, the diffusive and dispersive models predict less condensate flux than the total moisture influx due to the weak axial moisture transport to the condensation drainage area in the unheated drift sections. The vapor must leave the closed drift air space in superheated vapor form, which is modeled accordingly in MULTIFLUX. This vapor transport is possible via a minute, rather insignificant total pressure increase in the closed rockmass domain. Moisture convection in the convective model, which is the most realistic of all three models can, however, remove the moisture and all vapor inflow from the rock along the drift length by condensation without the need for any increase in the total pressure.

An asymmetry is also seen in the condensate distribution between the two drift ends, as shown in Figure 14. Condensation forms at about $1.75 \times 10^{-6} \mathrm{~kg} / \mathrm{s}-\mathrm{m}$ rate at the waste packages close to the short unheated section while there is no condensation at the other end connected to the longer unheated section. At year 5000, condensation appears at multiple waste package locations, e.g., at $118 \mathrm{~m}$ distance into the emplacement zone from the short unheated end with a condensation rate of $3.3 \times 10^{-5} \mathrm{~kg} / \mathrm{s}-\mathrm{m}$, shown in Figure 14. At the same distance into the emplacement zone from the long unheated section, the condensation rate is zero. 
Several versions of design for the emplacement drifts have been published for Yucca Mountain regarding the offset of the waste packages from the ends forming the unheated sections. The present study results show the sensitivity to the length of the unheated sections in both temperature (Figures 9 and 10), and relative humidity distribution (Figures 11 and 12) as well as in the appearance of water condensation (Figures 13 and 14). This sensitivity was previously studied [6] and is again confirmed in the current numerical results.

The results in Figure 15 show that the diffusive model provides the least amount of condensation which is due to the high axial transport resistance and the removal of moisture in superheated steam form. The convective model shows a smooth condensation trend until year 600. At year 600, the percolation flux at the surface increases according to the TOUGH2 model input specifications [3], causing a gradual, pronounced but still smooth change. We consider the smoothness of the curve from the convective model a manifestation of model stability and robustness. Although all three models are solved with the same iteration parameters in MULTIFLUX, it is a pleasing fact that our best, most sophisticated model provides the most stable and reasonable result.

Figures 16 and 17 show the drift wall heat flux distributions for the convective, diffusive and dispersive models for six selected time instants outside and inside the drip shields, respectively. Figures 18 and 19 show the drift wall moisture flux distributions for the convective, diffusive and dispersive models outside and inside the drip shields, respectively.

A comparison between the three different model results in Figures 16 through 19 show the effects of three different model assumptions for the in-drift transport processes. As the in-rock and in-drift model-elements interact differently, the coupled, balanced boundary conditions will converge to different distributions. The difference can be quite significant, underlining the importance of using a fully-coupled model. 


\section{CONCLUDING REMARKS}

An iterative, numerical solution method is presented using a turbulent airflow as well as heat and moisture transport network model that is coupled to porous and fractured rockmass model.

A successful, converging solution is presented for the fully-coupled solution between a porous-medium model in TOUGH2 for the near-field fractured-rock domain and an integratedparameter CFD model in MULTIFLUX for the in-drift domain. The solution is applied to a complex thermo-hydrologic-air flow problem at Yucca Mountain for a full emplacement drift, embedded in a mountain-scale rockmass with edge cooling.

The natural, three-dimensional air flow field is explicitly solved in MULTIFLUX for the drift air space during post-closure. The model results show that natural, buoyancy-driven axial air flow loops are formed along the full emplacement drift. Large-eddy turbulent flow, as opposed to small-eddy flow seems to dominate the drift air space for at least 5000 years, as evidenced by the three-dimensional velocity field distributions.

Simulation results are given for temperature, humidity, heat flow, moisture flow, and condensation rates on the drift wall along the full length of an emplacement drift from three different in-drift models using three different assumptions for comparison, ranging from simplistic to advanced. The convective model is the most realistic and defendable, therefore, it will be likely the most preferable in future modeling studies. The present study shows that such an ambitious model, an integrated-parameter CFD coupled to TOUGH2, can indeed be selected and solved.

The results are somewhat asymmetrical along the length of the emplacement drift due to the different length of unheated sections at the two ends. Condensation under the drip shields around the waste packages appear much earlier (at year 1000) closer to the short unheated drift end than to the other end. This fact indicates that the short unheated drift end, an empty drift 
section of $15 \mathrm{~m}$, is not long enough to condense the vapor driven to that drift end by air convection, causing condensation that invades the emplacement zone. On the other drift end with the long unheated section of $60 \mathrm{~m}$, a significantly larger amount of condensate is attracted, all outside the emplacement zone. This finding highlights the importance of selecting a longenough offset of the emplacement zones filled with waste packages from the unheated drift ends if condensation on the metal containers are to be avoided at early time periods.

\section{ACKNOWLEDGEMENTS}

This manuscript has been authored by Lawrence Berkeley National Laboratory and University of Nevada, Reno, under Contract No. DE-AC02-05CH11231 with the U.S. Department of Energy. Financial support from Nye County, Nuclear Waste Project Office is also acknowledged. The United States Government retains and the publisher, by accepting the article for publication, acknowledges that the United States Government retains a non-exclusive, paid-up, irrevocable, worldwide license to publish or reproduce the published form of this manuscript, or allow others to do so, for United States Government purposes. The views expressed in this article are those of the authors and do not necessarily reflect the views or policies of the United States Department of Energy, Lawrence Berkeley National Laboratory, or the University of Nevada, Reno. 


\section{NOMENCLATURE}

qh $\quad$-rock heat flux vector

$q m_{i} \quad$-rock moisture flux vector

$t \quad$-time vector

$T \quad$-rock temperature vector

$P_{i} \quad$-rock partial vapor pressure vector

Tc rock temperature variation vector (central condition around which the NTCF model is determined).

$P c \quad$-rock partial vapor pressure variation vector (central condition around which the NTCF model is determined).

$h h \quad$ - rock cell temperature-driven admittance matrix of heat flux

hm - rock cell vapor pressure-driven admittance matrix of heat flux

$m h \quad$ - rock cell temperature-driven admittance matrices for the moisture flux

$\mathrm{mm} \quad$ - rock cell vapor pressure-driven admittance matrices for the moisture flux

$\rho \quad$-density of moist air

c -specific heat of moist air

a -molecular or eddy thermal diffusivity for laminar or turbulent flow

$\dot{q}_{h} \quad$-latent heat source or sink for condensation or evaporation

$T \quad$-temperature field

$x, y, z$-Cartesian coordinate system

$\rho_{v}$-partial density of water vapor

D -molecular or eddy diffusivity for vapor for laminar or turbulent flow

$\dot{q}_{c m}$-moisture source or sink due to condensation or evaporation 
$\dot{q}_{s m}$-vapor flux in superheated steam form

$P_{v} \quad$-partial vapor pressure

$P_{s}$-saturated vapor pressure

$P_{b}$-barometric pressure 


\section{REFERENCES}

1. Danko, G., Birkholzer, N., Bahrami, D. and Halecky, N. 2010. Temperature, Humidity and Air Flow in the Emplacement Drifts Using Convection and Dispersion Transport Models. Journal of Nuclear Technology, July 2010, Vol. 171, 74-87.

2. Sandia National Laboratory (SNL) 2008. Multiscale Thermohydrologic Model. ANL-EBSMD-000049, Rev. 03, Las Vegas, Nevada: Sandia National Laboratories.

3. Birkholzer, J., Halecky, N., Webb, S.W., Peterson, P.F., Bodvarsson, G.S. 2006. The Impact of Natural Convection on Near-Field TH Processes at Yucca Mountain. Proceedings, 11th International High-Level Nuclear Waste Conference, April, Las Vegas, NV.

4. Birkholzer, J.T., Halecky, N., Webb, S.W., Peterson, P.F., Bodvarsson, G.S. 2008. A Modeling Study Evaluating the Thermal-Hydrological Conditions in and Near Waste Emplacement Tunnels at Yucca Mountain. Journal of Nuclear Technology, July, 163.

5. Sandia National Laboratory (SNL), 2007. In-drift natural convection and condensation. Yucca Mountain Project Report, MDL-EBS-MD-000001 REV 00 AD 01, Las Vegas, Nevada: Sandia National Laboratories.

6. Danko G., Bahrami D., Birkholzer J. 2006. The Effect of Unheated Sections on Moisture Transport in the Emplacement Drift. Proceedings, 11th International High-Level Radioactive Waste Management Conference, Las Vegas, NV, pp. 1-8.

7. Danko, G., Birkholzer, J., and Bahrami, D. 2008. Coupled In-Rock and In-Drift Hydrothermal Model Study for Yucca Mountain. Journal of Nuclear Technology, July, Vol. 163, pp. 110-128. 
8. Pruess, K., C. Oldenburg, and G. Moridis, 1999. TOUGH2 User's Guide, Version 2.0. Report LBNL-43134, Lawrence Berkeley National Laboratory, Earth Sciences Division, Berkeley, California.

9. Danko, G., 2006. Functional or Operator Representation of Numerical Heat and Mass Transport Models, Journal of Heat Transfer, February 2006, Vol. 128, 162-175.

10. Bahrami, D. and Danko, G. 2006. Thermal-Hydrologic Model of an Alternative Waste Package Design for Yucca Mountain Repository. Journal of Nuclear Technology, May, Vol. 154, p. $247-264$.

11. Danko, G. 2008. MULTIFLUX V5.0 Software Qualification Documents. Software Tracking Number: 1002-5.0-00, Prepared for the Berkeley National Laboratory at University of Nevada, Reno. 


\section{APPENDIX: GOVERNING EQUATIONS}

Governing equations in the NTCF model in MULTIFLUX [11]

The following equations may be used as surrogate NTCF models which can temporarily represent TOUGH2 result for a momentary boundary condition on the rock-air interface. The NTCF models are matrix equations for $q h$ and $q m$. Eight different model types maybe selected from in the current software version:

Model Type 1: Linear, temperature-driven process model

$$
\begin{aligned}
& q h=q h_{c}+h h 1 \cdot *\left(T-T_{c}\right) \\
& q m=q m_{c}+m h 1 * *\left(T-T_{c}\right)
\end{aligned}
$$

Model Type 2: Linear, partial vapor-pressure driven process model

$$
\begin{aligned}
& q h=q h_{c}+h m l * *\left(P-P_{c}\right) \\
& q m=q m_{c}+m m l * *\left(P-P_{c}\right)
\end{aligned}
$$

Model Type 3: Linear, temperature and partial vapor-pressure driven process model

$$
\begin{aligned}
& q h=q h_{c}+h h 1 . *\left(T-T_{c}\right)+h m l \cdot *\left(P-P_{c}\right) \\
& q m=q m_{c}+m h l \cdot *\left(T-T_{c}\right)+m m l * *\left(P-P_{c}\right)
\end{aligned}
$$

Model Type 4: Nonlinear, temperature and partial vapor-pressure driven process model 


$$
\begin{aligned}
& q h=q h_{c}+h h 1 *\left(T-T_{c}\right)+T . *\left[h m l^{*}\left(P-P_{c}\right)\right] \\
& q m=q m_{c}+m h 1 *\left(T-T_{c}\right)+T . *\left[m m l^{*}\left(P-P_{c}\right)\right]
\end{aligned}
$$

Model Type 5: Nonlinear, temperature driven process model

$$
\begin{aligned}
& q h=q h_{c}+h h 1 * *\left(T-T_{c}\right)+\mathrm{T} . *\left[h h 2 *\left(T-T_{c}\right)\right] \\
& q m=q m_{c}+m h 1 *\left(T-T_{c}\right)+T . *\left[m h 2 *\left(T-T_{c}\right)\right]
\end{aligned}
$$

Model Type 6: Nonlinear temperature and partial vapor-pressure driven process model

$$
q h=q h_{c}+h h 1 * *\left(T-T_{c}\right)+T . *\left[h h 2 * *\left(T-T_{c}\right)\right]+T . *\left[h m 1 * *\left(P-P_{c}\right)\right]
$$

\section{(A.11)}

$q m=q m_{c}+m h 1 * *\left(T-T_{c}\right)+T . *\left[m h 2 . *\left(T-T_{c}\right)\right]+T . *\left[m m \cdot *\left(P-P_{c}\right)\right]$

\section{(A.12)}

Model Type 7: Nonlinear, temperature and partial vapor-pressure driven process model

$$
\begin{aligned}
& q h=q h_{c}+T . *\left[h m 1 *\left(P-P_{c}\right)\right]+T . * T . *\left[h m 2 *\left(P-P_{c}\right)\right] \\
& q m=q m_{c}+T . *\left[m m 1 * *\left(P-P_{c]}\right)+T . * T . *\left[m m 2 . *\left(P-P_{c}\right)\right]\right.
\end{aligned}
$$

Model Type 8: Nonlinear, temperature and partial vapor-pressure driven process model 


$$
\begin{aligned}
& q h=q h_{c}+h h 1 . *\left(T-T_{c}\right)+T . * T . *\left[h m 1 . *\left(P-P_{c}\right)\right] \\
& q m=q m_{c}+m h 1 . *\left(T-T_{c}\right)+T . * T . *\left[m m 1 . *\left(P-P_{c}\right)\right]
\end{aligned}
$$

Different model types may be selected for heat and moisture transport. For example, a Type 4 model in Eq.(A.7) for heat and a Type 1 model in Eq.(A.2) for moisture are often used together in YMP applications [1,7].

Governing Equations in the CFD module in MULTIFLUX [11]

The Navier-Stokes momentum balance equation for 3D flow of the bulk air-moisture mixture is used in a simplified from following [13]:

$$
\begin{aligned}
& \rho\left(\frac{\partial v_{x}}{\partial t}+\mathbf{v} \cdot \nabla v_{x}\right)=\rho g_{x}-\frac{\partial P b}{\partial x}+F_{x} \\
& \rho\left(\frac{\partial v_{y}}{\partial t}+\mathbf{v} \cdot \nabla v_{y}\right)=\rho g_{y}-\frac{\partial P b}{\partial y}+F_{y} \\
& \rho\left(\frac{\partial v_{z}}{\partial t}+\mathbf{v} \cdot \nabla v_{z}\right)=\rho g_{z}-\frac{\partial P b}{\partial z}+F_{z},
\end{aligned}
$$

where $v_{x}, v_{y}, v_{z}$ are velocity components of vector $v$,

$g_{x}, g_{y}, g_{z}$ are gravitational forces which include buoyancy in $\mathrm{x}, \mathrm{y}$, and $\mathrm{z}$ directions, and $F_{x}, F_{y}, F_{z}$ are viscous terms.

The viscous terms in Eqs. (A.17-A.19) are expressed with the viscous normal-stress $(\sigma)_{v}$ and shear-stress $(\tau)$ components as follows:

$$
F_{x}=\frac{\partial\left(\sigma_{x x}\right)_{v}}{\partial x}+\frac{\partial \tau_{y x}}{\partial y}+\frac{\partial \tau_{z x}}{\partial z}
$$




$$
\begin{aligned}
& F_{y}=\frac{\partial \tau_{x y}}{\partial x}+\frac{\partial\left(\sigma_{y y}\right)_{v}}{\partial y}+\frac{\partial \tau_{z y}}{\partial z} \\
& F_{x}=\frac{\partial \tau_{x z}}{\partial x}+\frac{\partial \tau_{y z}}{\partial y}+\frac{\partial\left(\sigma_{z z}\right)_{v}}{\partial z}
\end{aligned}
$$

The viscous force terms in Eqs. (A.20-A.22) are integrated along the grid lines of the flow channels and expressed as a function of the convective air flow components in the emplacement drift.

The simplified energy balance equation in the CFD module is as follows for an $x$ directional flow with $v_{i}$ velocity in a flow channel of cross section $d y$ by $d z$ (and with no convective heat transport in $y$ and $z$ directions while considering the $x$-directional flow):

$$
\rho c \frac{\partial T}{\partial t}+\rho c v_{i} \frac{\partial T}{\partial x}=\rho c a \frac{\partial^{2} T}{\partial x^{2}}+\rho c a \frac{\partial^{2} T}{\partial y^{2}}+\rho c a \frac{\partial^{2} T}{\partial z^{2}}+\dot{q}_{h}
$$

In Eq. (A.23), $\rho$ and $c$ are density and specific heat of moist air, respectively; $a$ is the molecular or eddy thermal diffusivity for laminar or turbulent flow; and $\dot{q}_{h}$ is the latent heat source or sink for condensation or evaporation.

The simplified moisture transport convection-diffusion equation in the CFD module is similar to Eq. (A.23) as follows:

$$
\rho \frac{\partial \omega}{\partial t}+\rho v_{i} \frac{\partial \omega}{\partial x}=\rho D \frac{\partial^{2} \omega}{\partial x^{2}}+\rho D \frac{\partial^{2} \omega}{\partial y^{2}}+\rho D \frac{\partial^{2} \omega}{\partial z^{2}}+q c+q s+q m
$$

Where $\quad \omega$ is the vapor mass fraction $\omega=\frac{P \cdot R a / R v}{P b-(1-R a / R v) \cdot P}$ $x, y, z$ are Cartesian coordinates, 
$t$ is time

$P$ is partial vapor pressure,

$P b$ is air total, barometric pressure,

$R a$ is gas constant for dry air,

$R v$ is gas constant for water vapor,

$\rho$ is density of moist air,

$D$ is the molecular or eddy diffusivity for vapor for laminar or turbulent flow,

$q c$ is the moisture source or sink due to condensation or evaporation at node $i$, and $q s$ is the vapor flux source or sink at node $i$ in superheated steam form.

These equations are integrated over a finite element. The details of the integrated components are given in the MULTIFLUX User's Manual [11]. The Integrated-parameter CFD solution approach allows for reducing the number of discretization elements in the computational domain. 


\section{FIGURES}

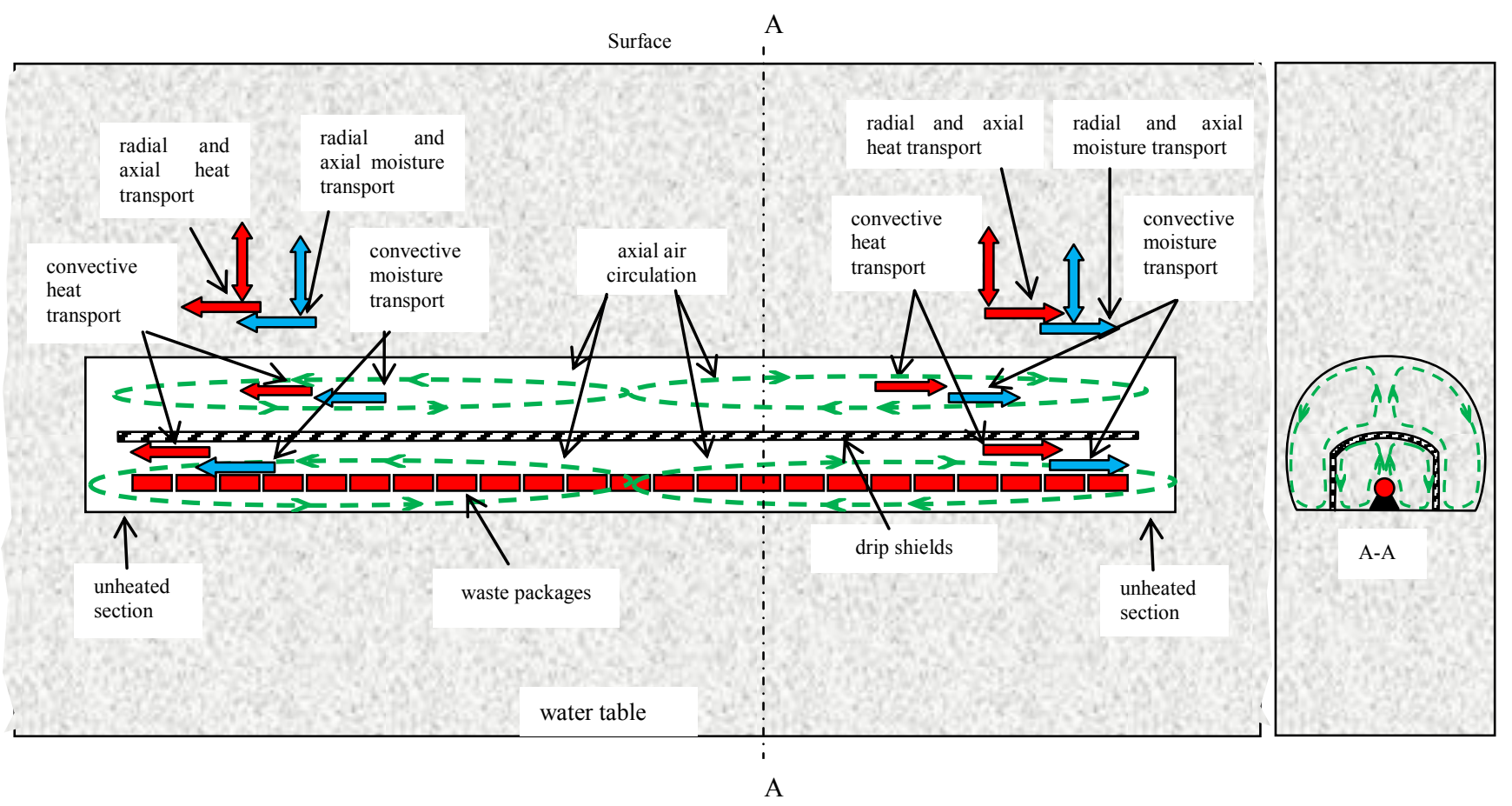

Figure 1. In-drift and in-rock transport processes in the coupled in-drift and in-rock model. 

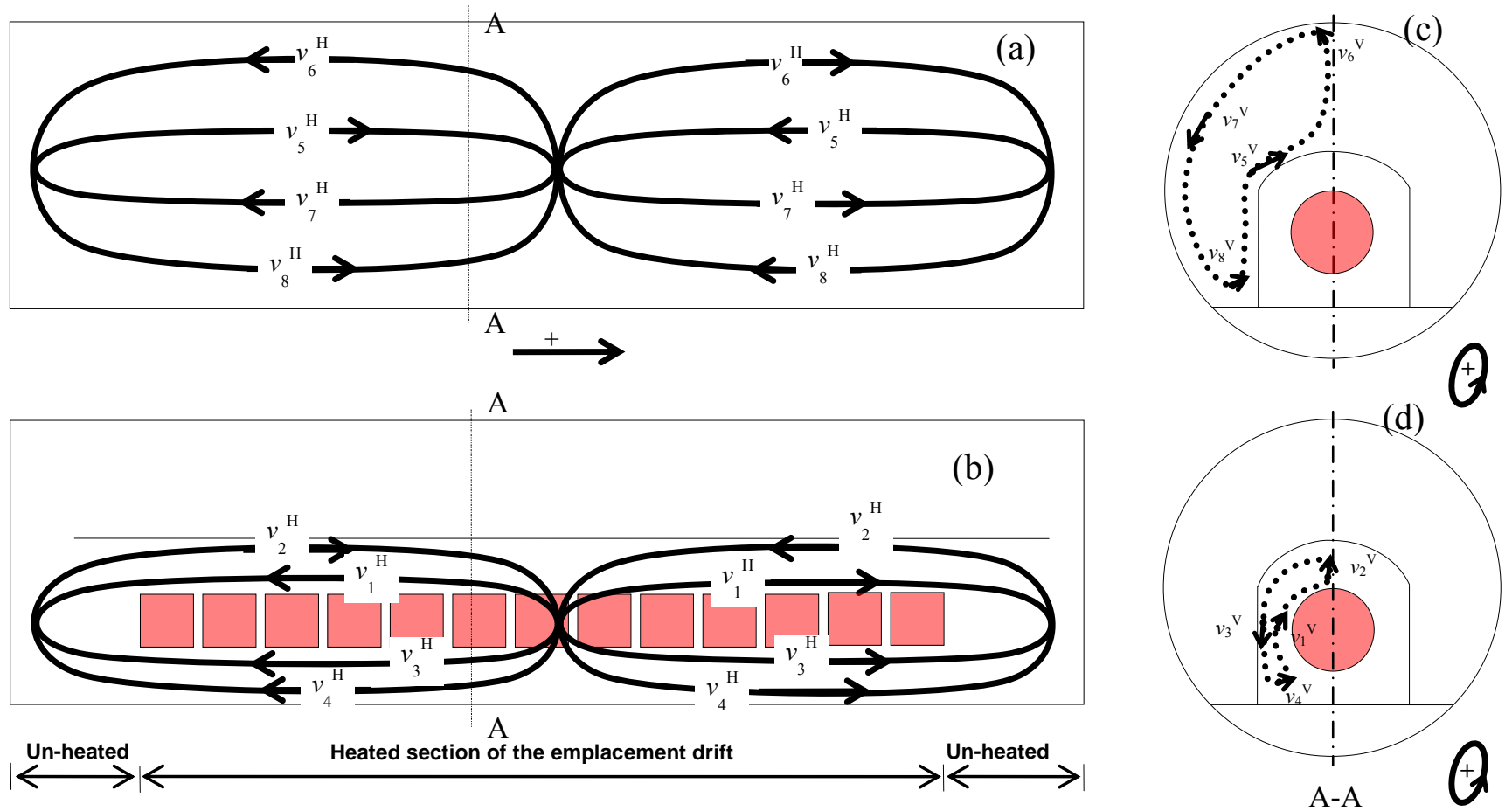

Figure 2.Schematic diagram of the natural, axial air-recirculation loops outside (a); and inside (b) the drip shields. Transversal air flow loops in the vertical cross section outside (c); and inside (d) the drip shields are also shown. 


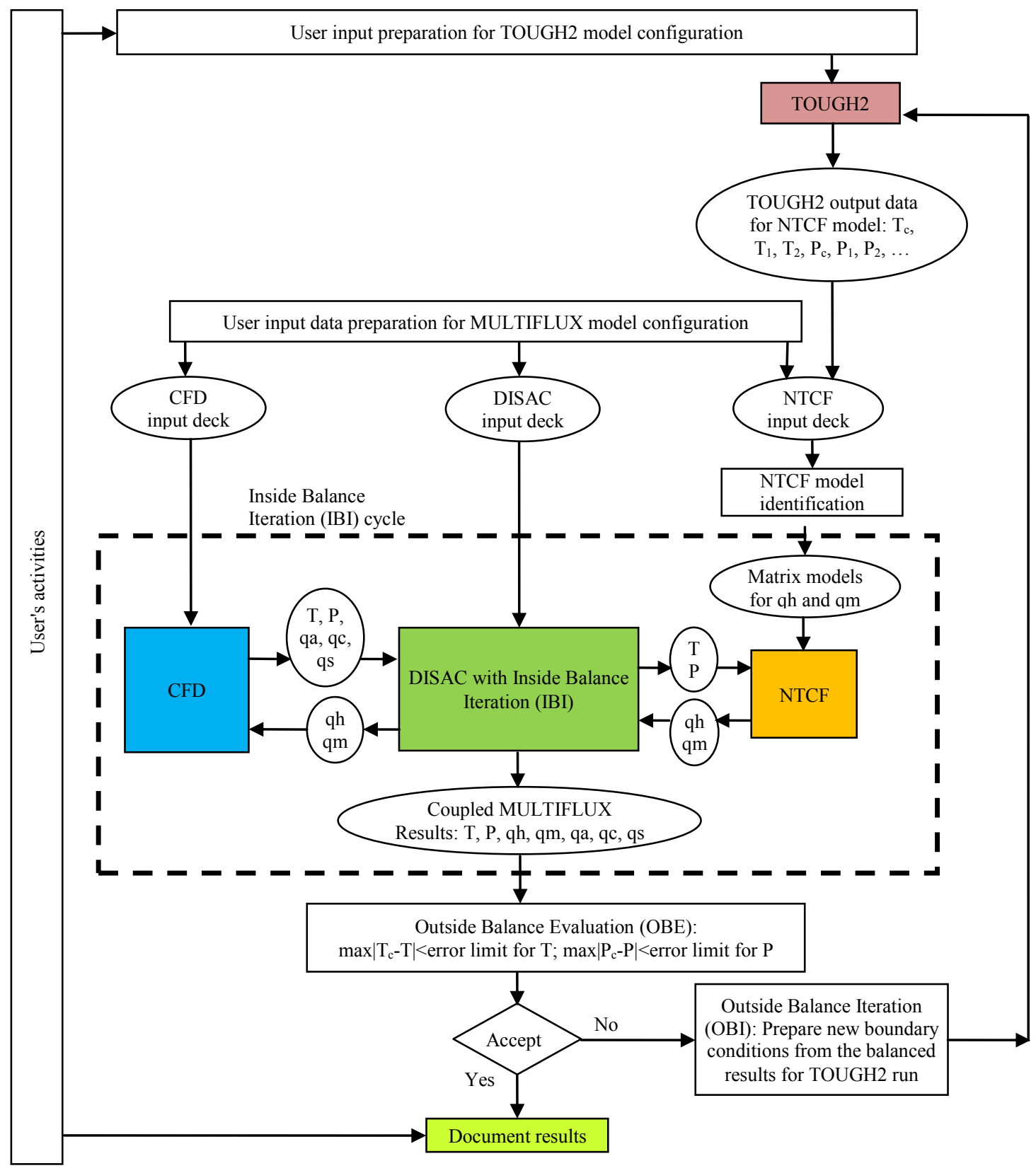

Figure 3. MULTIFLUX solution flowchart. 


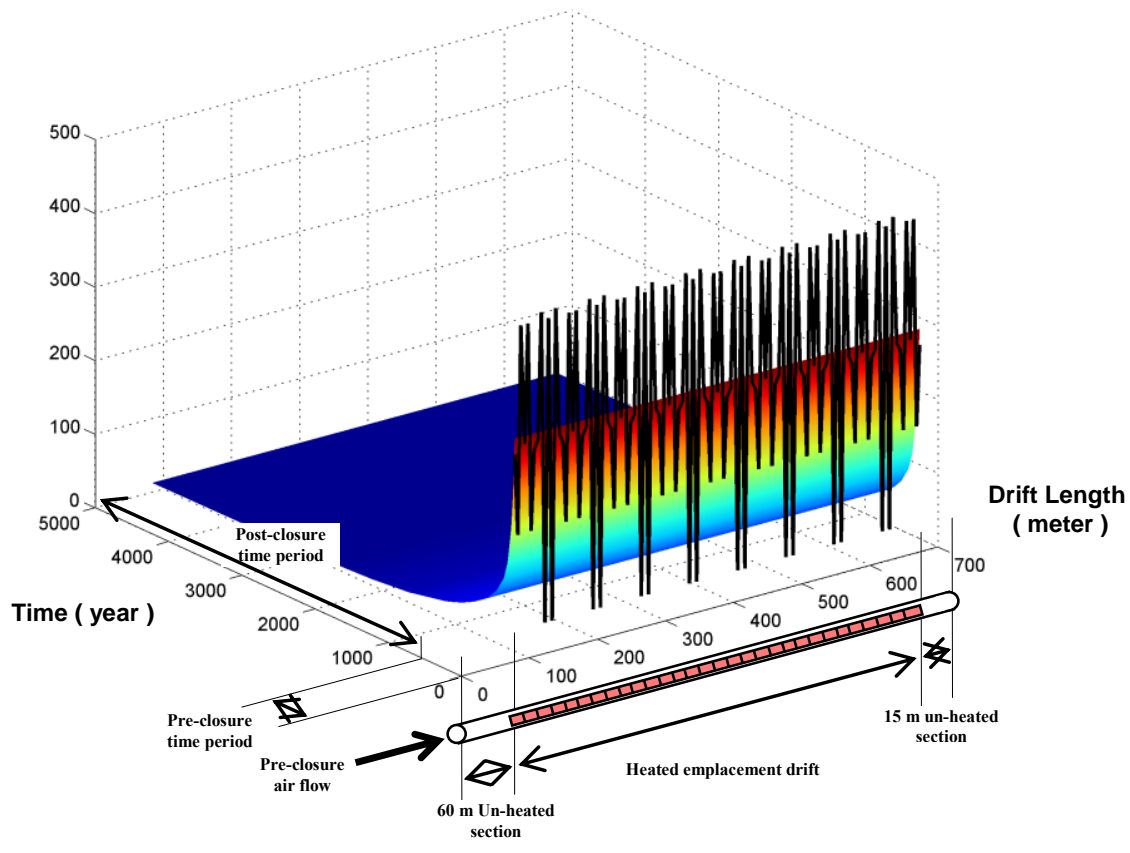

Figure 4. Variable, post-closure heat load per unit length for individual WPs at year 50 (solid line). 

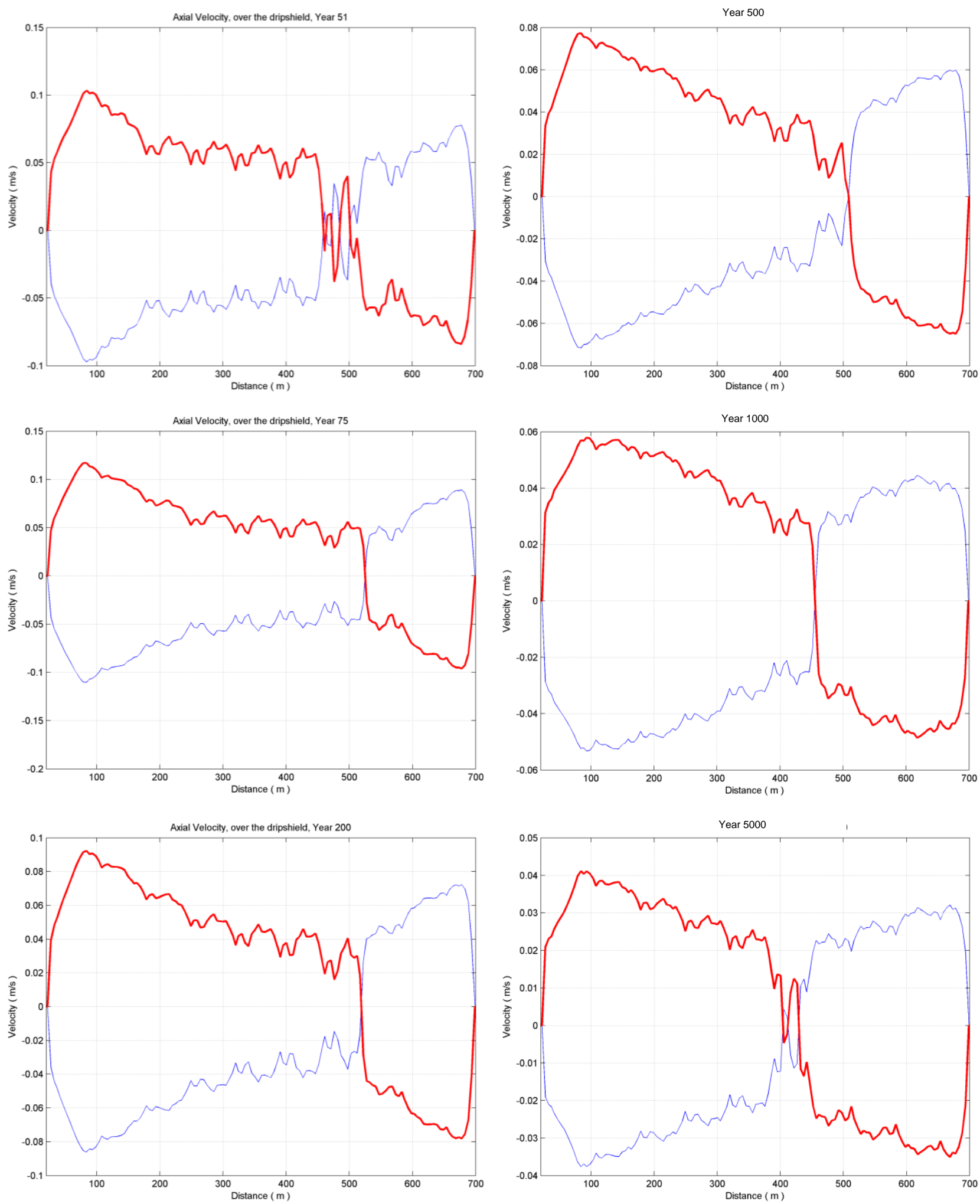

Figure 5. Axial air velocity variation outside the drip shields at selected post-closure time divisions. 

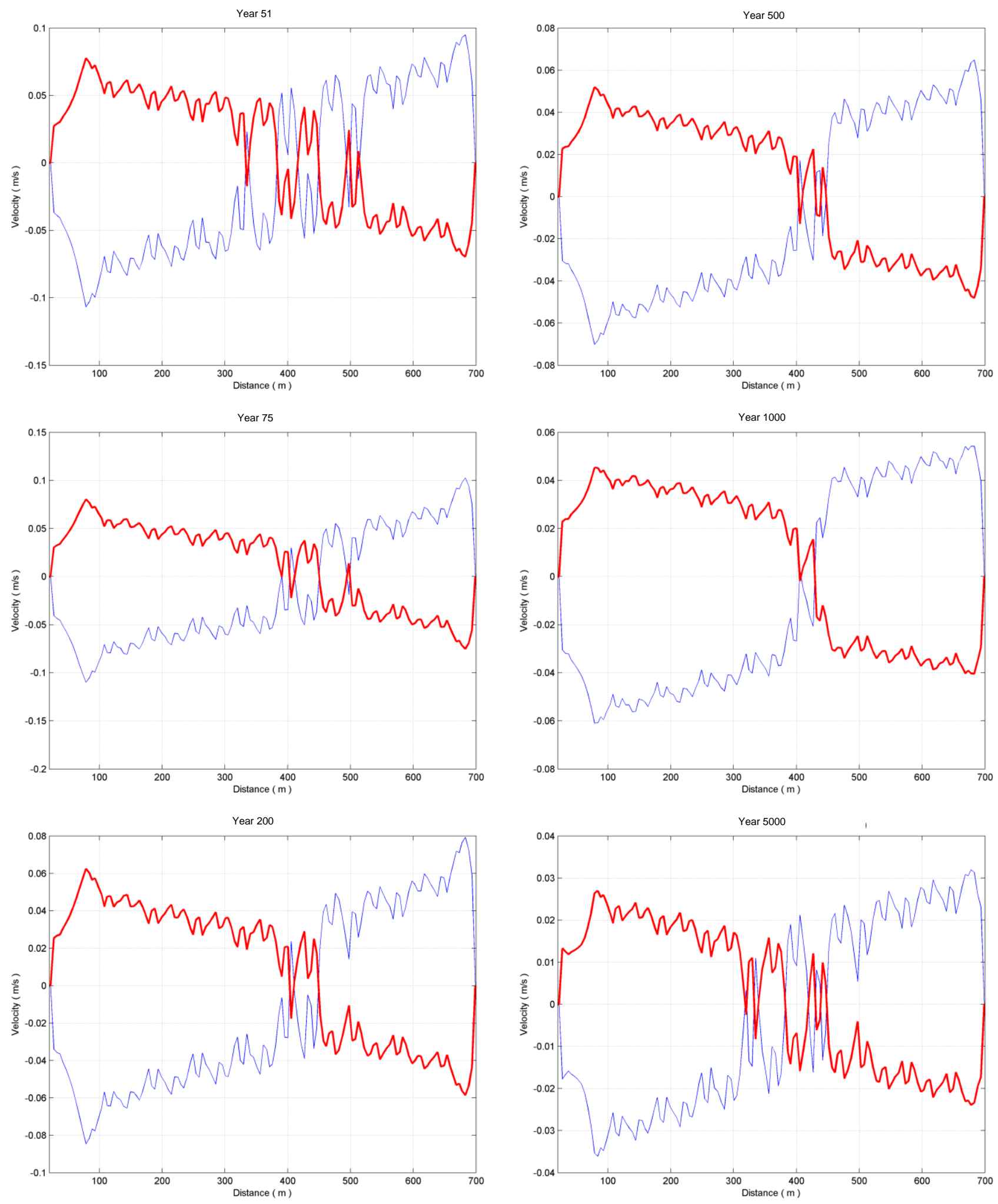

Figure 6. Axial air velocity variation inside the drip shields at selected post-closure time divisions. 

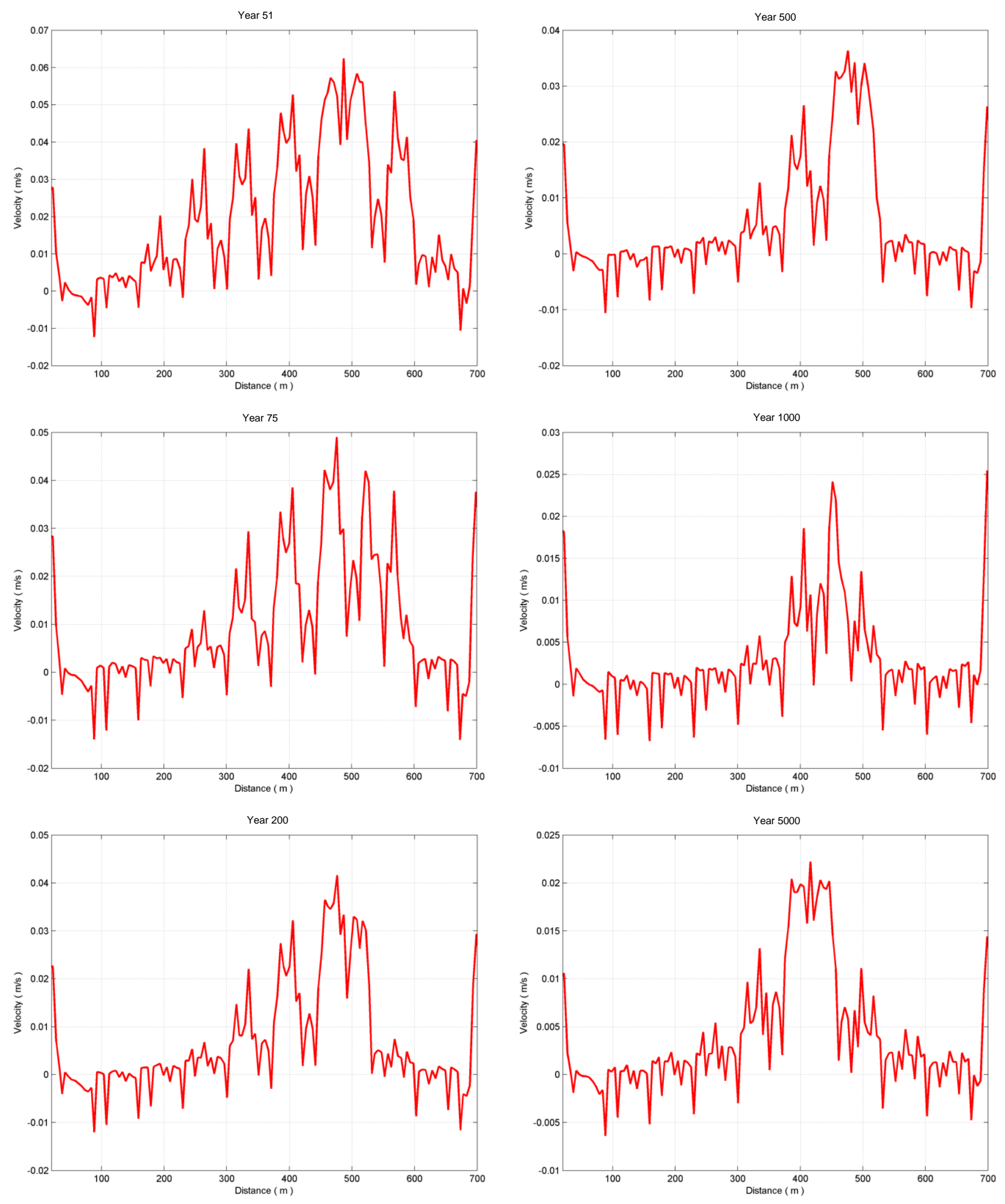

Figure 7. Transversal air velocity variation outside the drip shields at selected post-closure time divisions. 

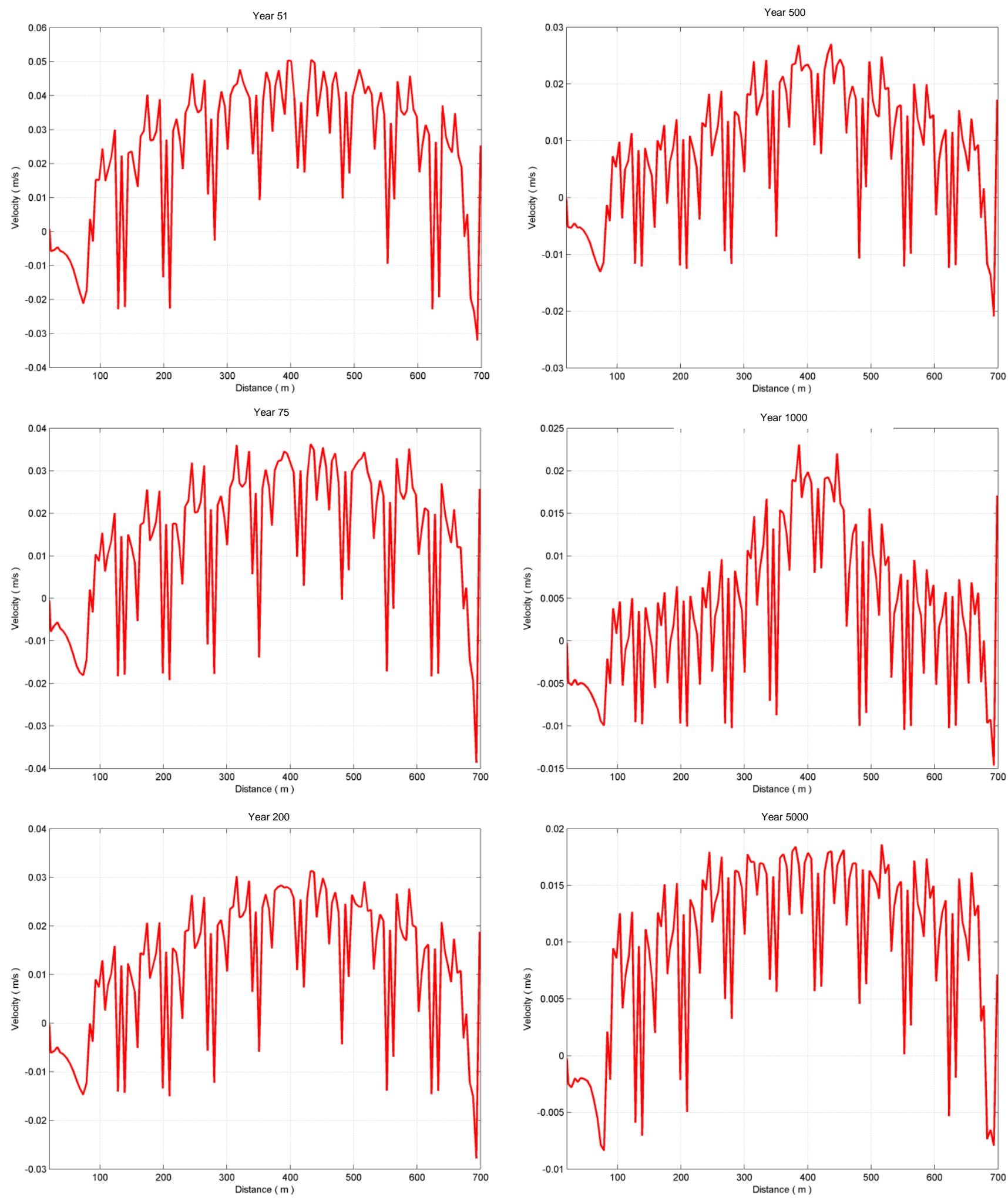

Figure 8. Transversal air velocity variation inside the drip shields at selected post-closure time divisions. 

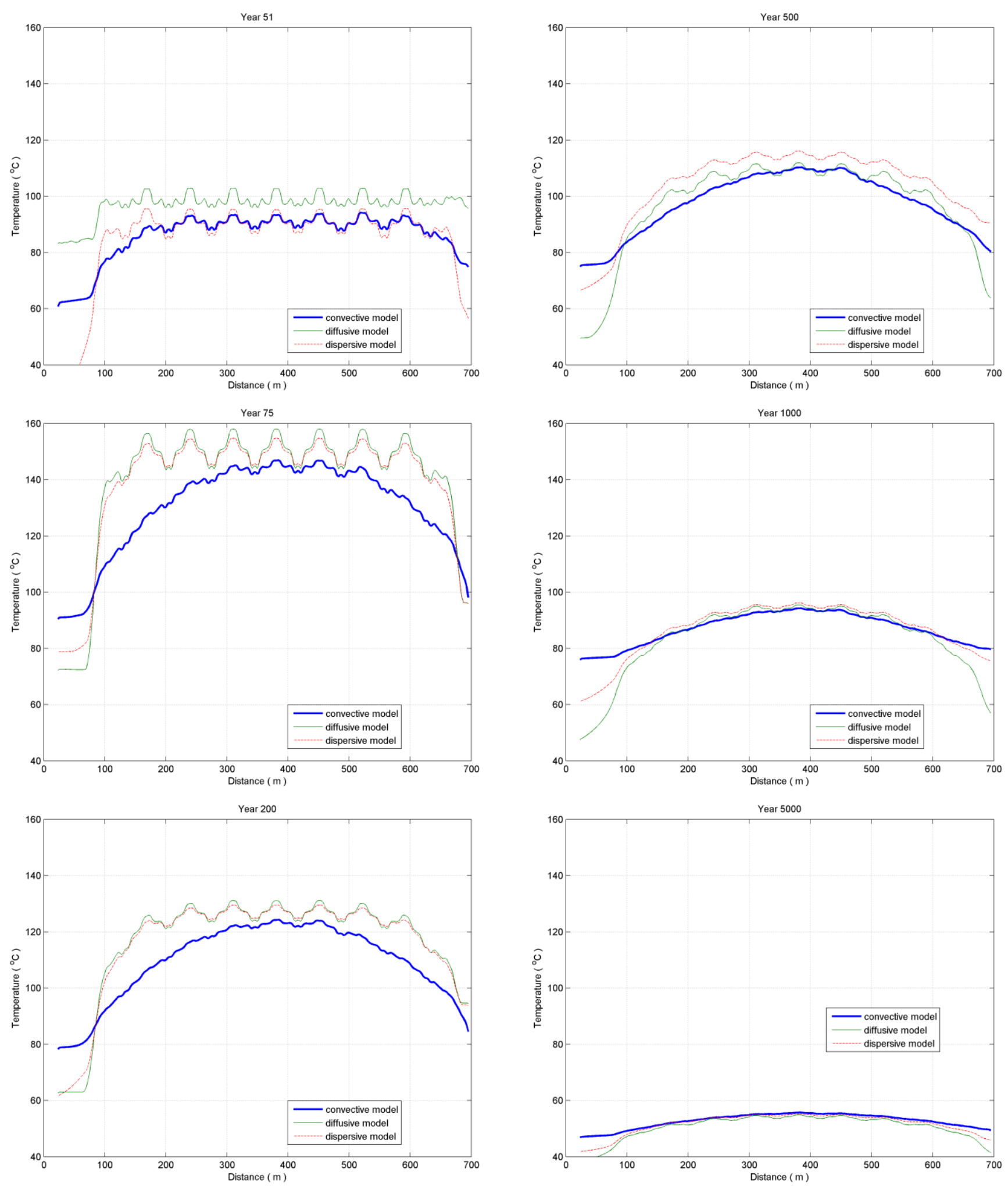

Figure 9. Drift wall temperature distribution in the airspace outside the drip shields at selected post-closure time divisions. 

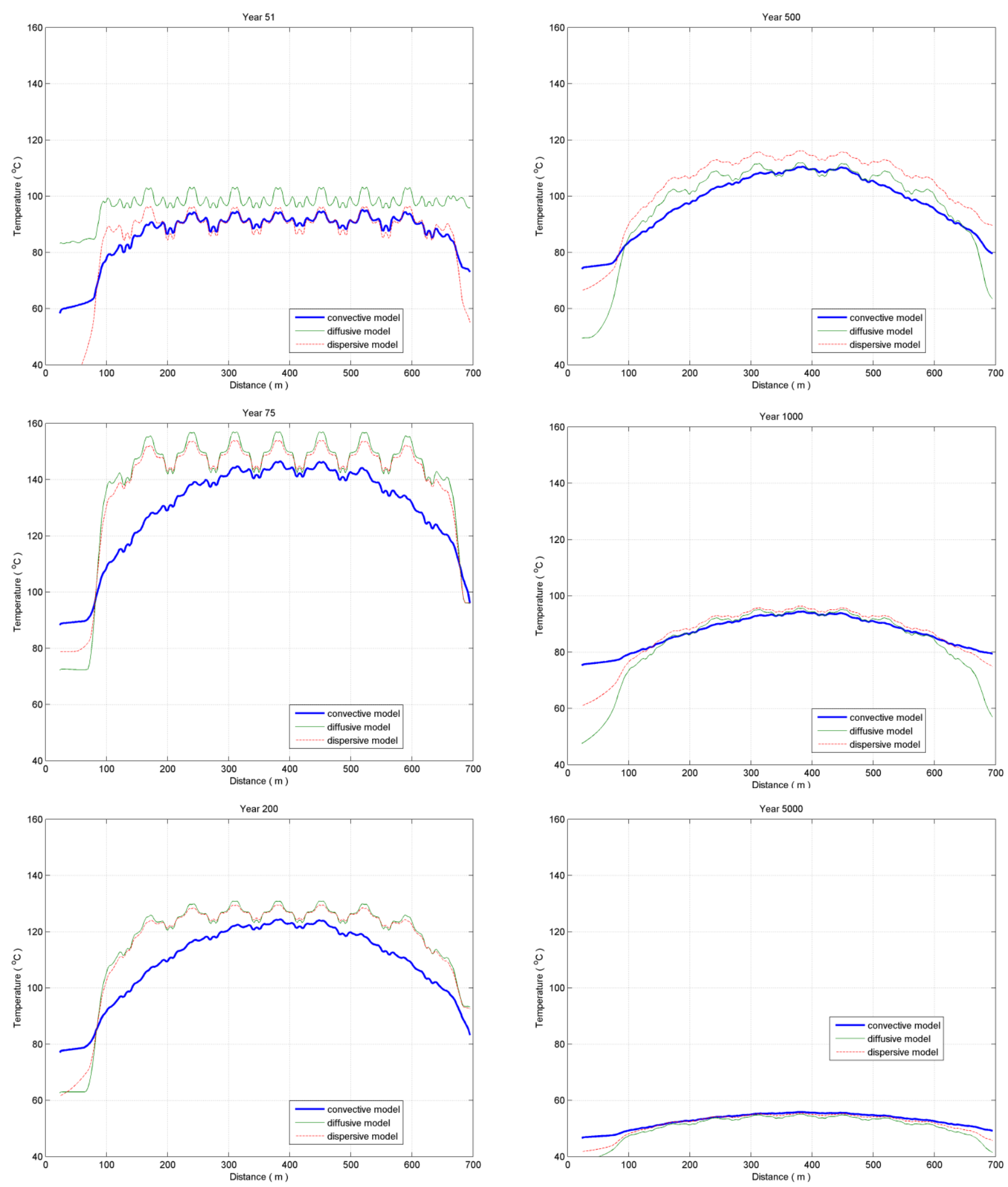

Figure 10. Drift invert temperature distribution in the airspace inside the drip shields at selected post-closure time divisions. 

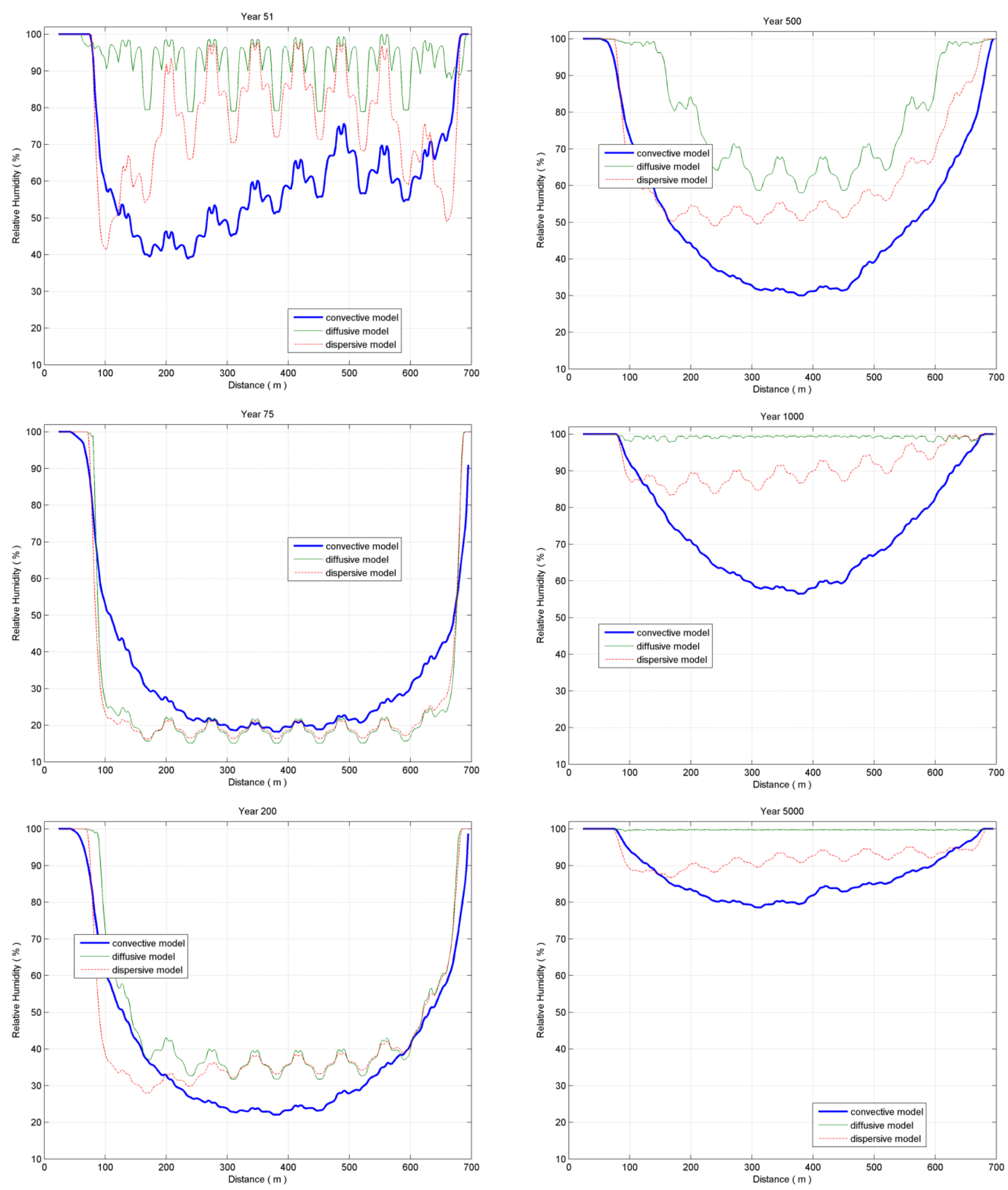

Figure 11. Drift wall relative humidity distribution in the airspace outside the drip shields at selected post-closure time divisions. 

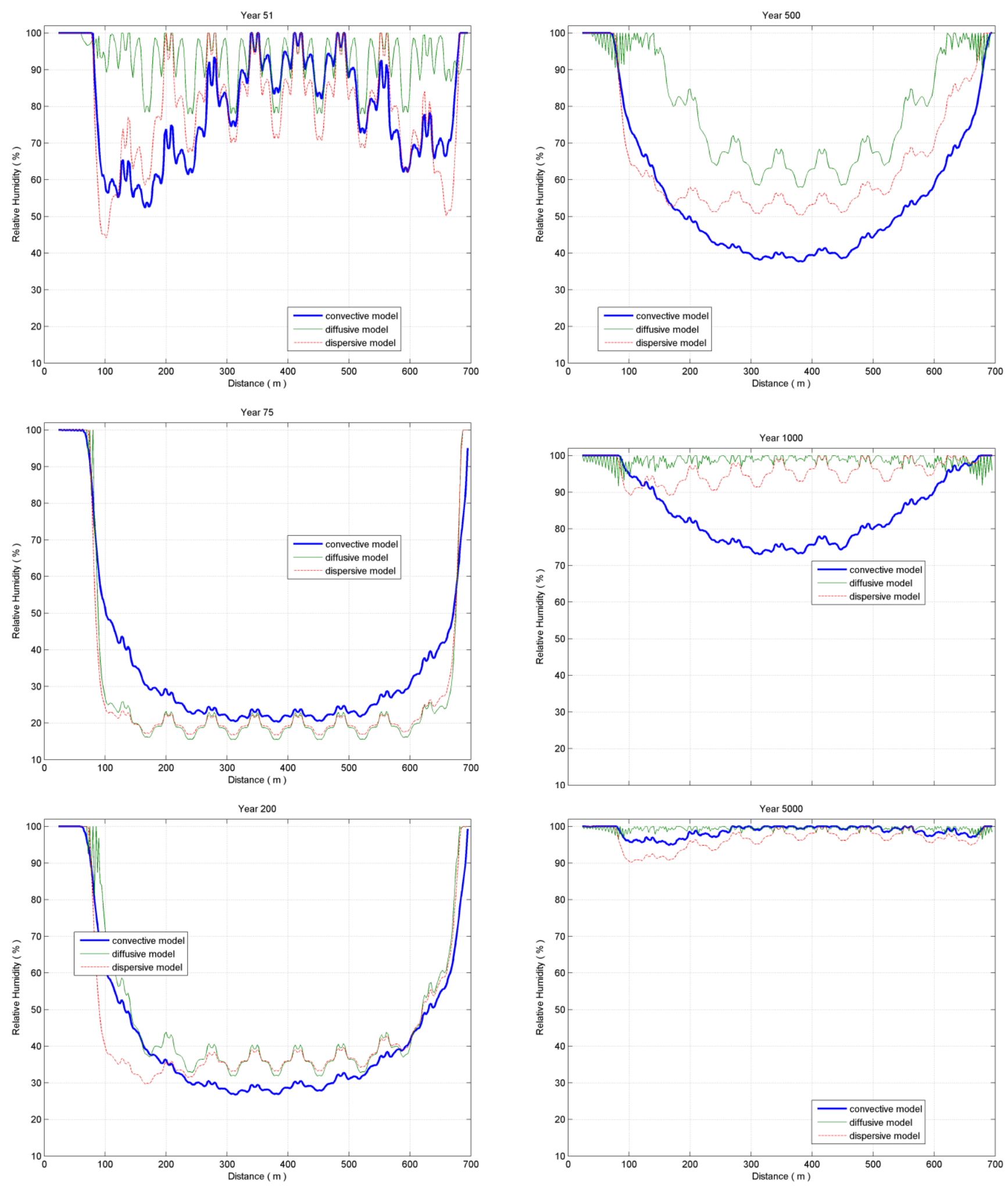

Figure 12. Drift invert relative humidity distribution in the airspace inside the drip shields at selected post-closure time divisions. 

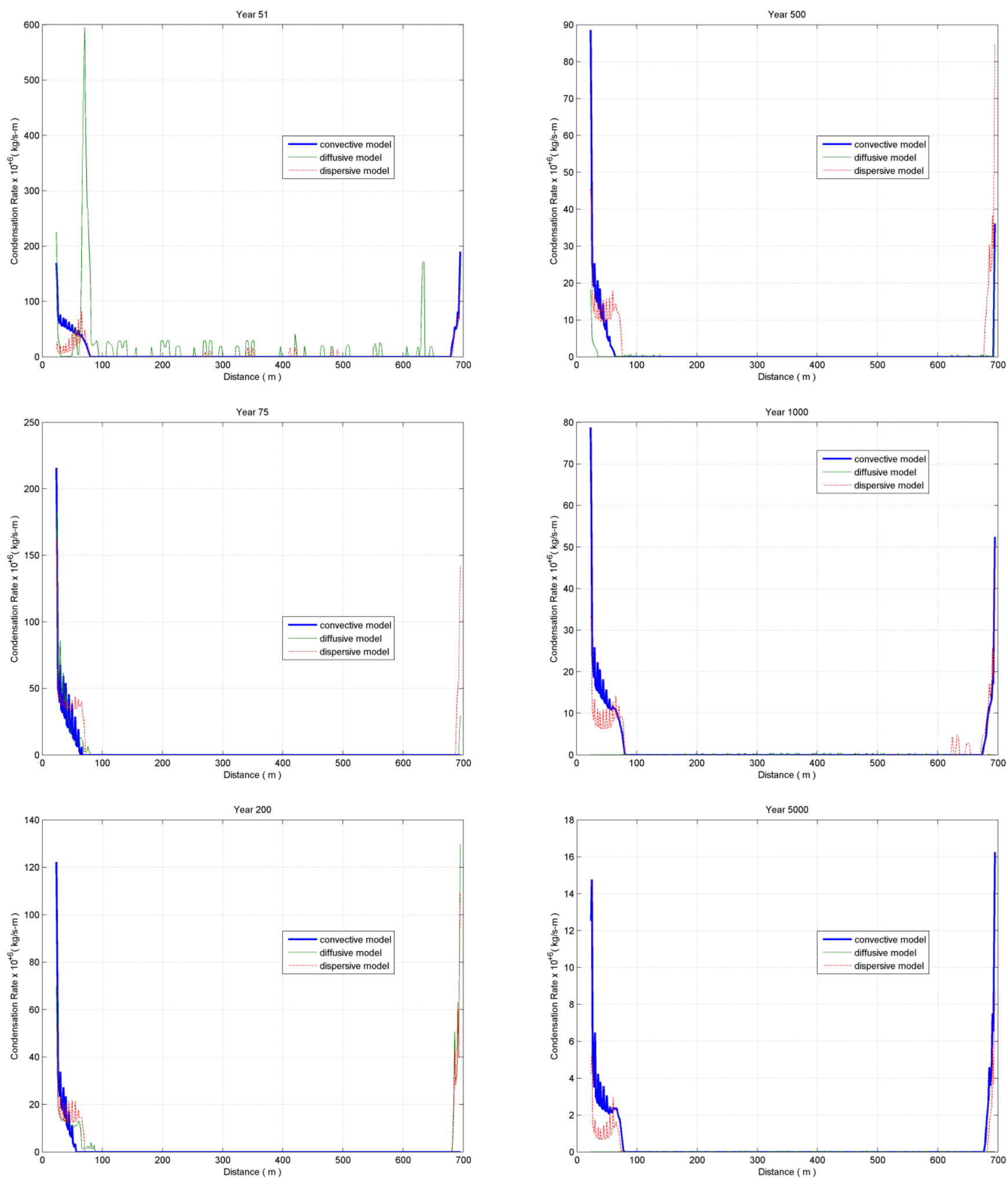

Figure 13. Condensation rate distribution outside the drip shields at selected post-closure time divisions. 

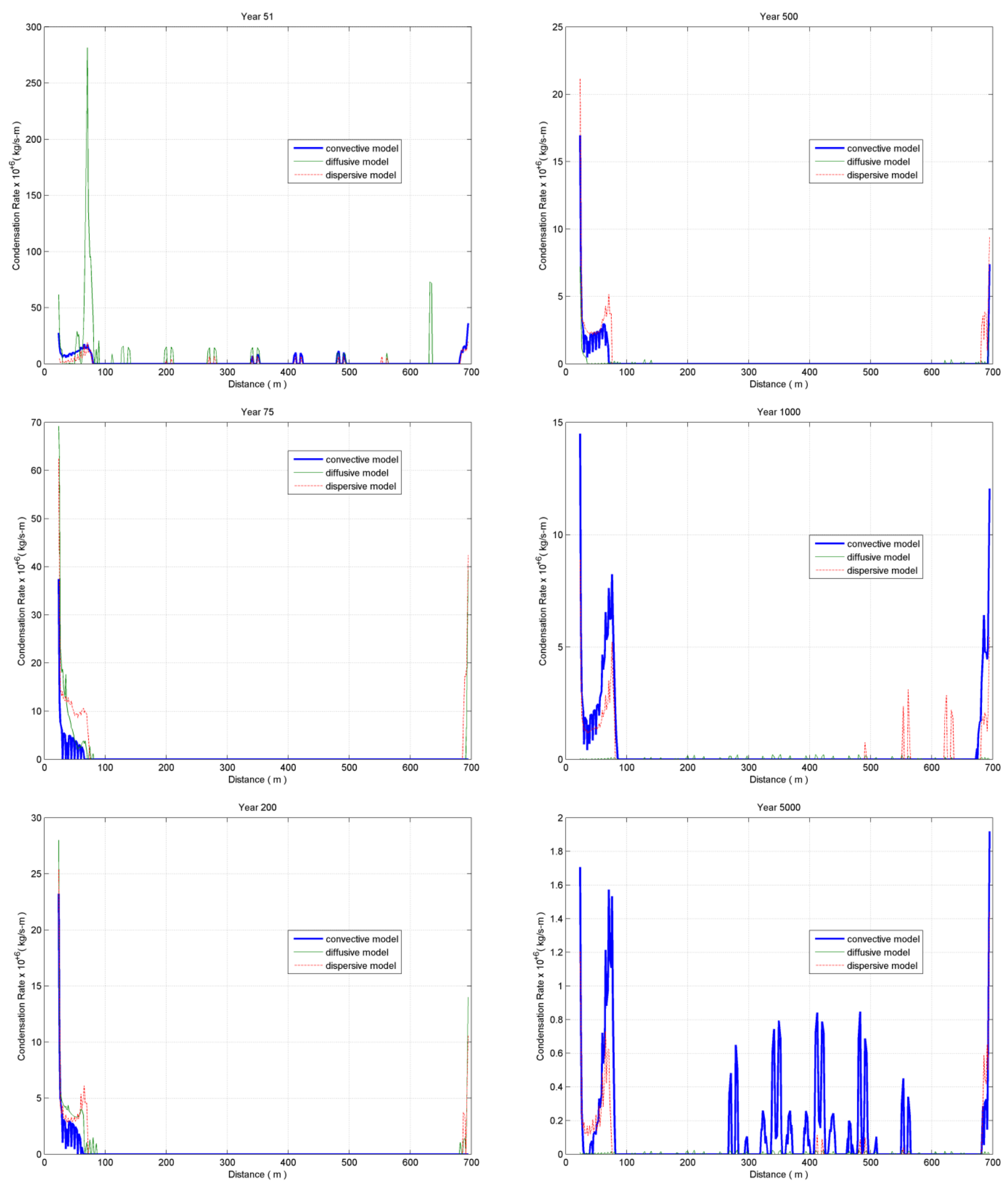

Figure 14. Condensation rate distribution inside the drip shields at selected post-closure time divisions. 


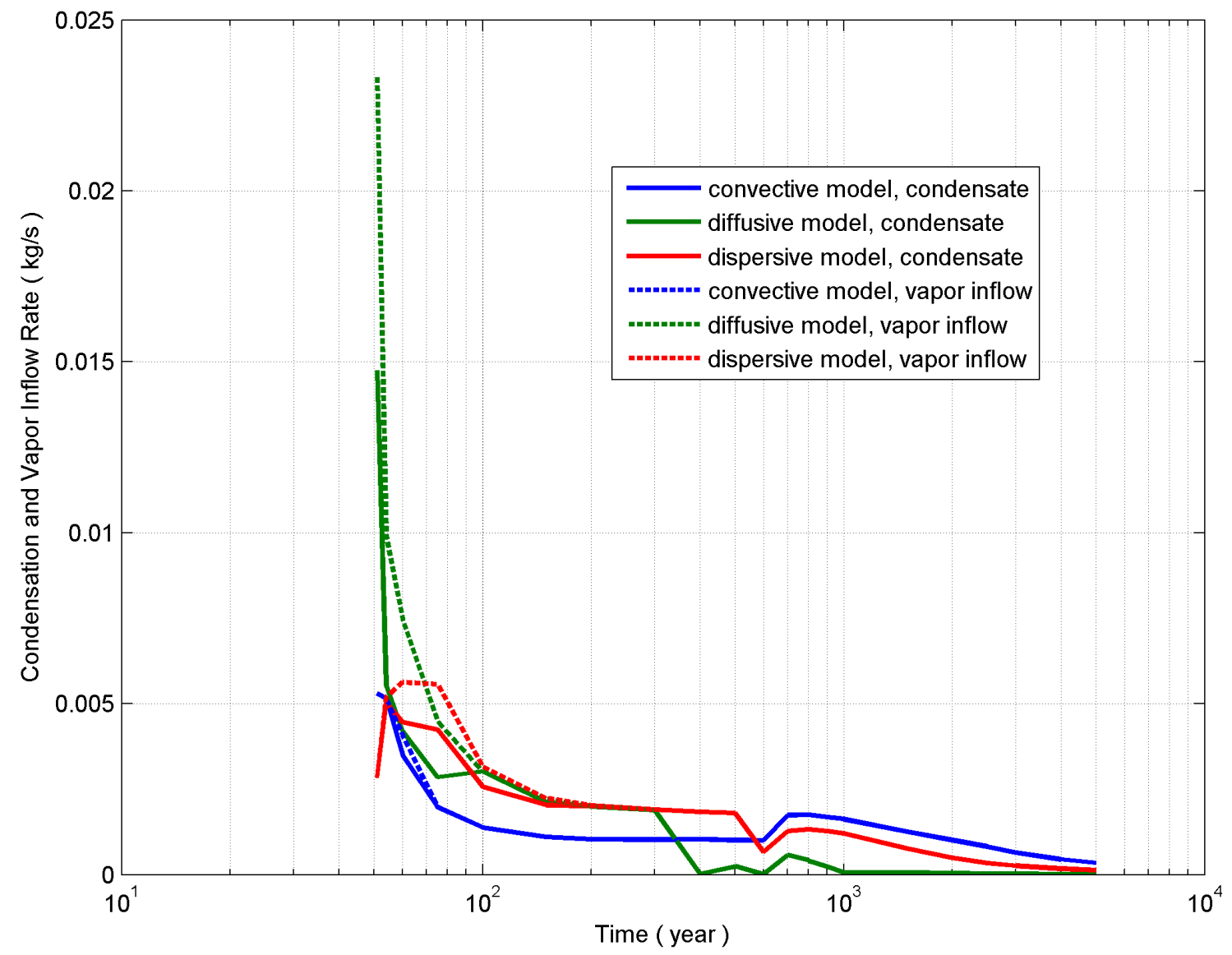

Figure 15. The evolution of total condensation rate (solid line) and vapor inflow rate (dashed line) in the emplacement drift. 

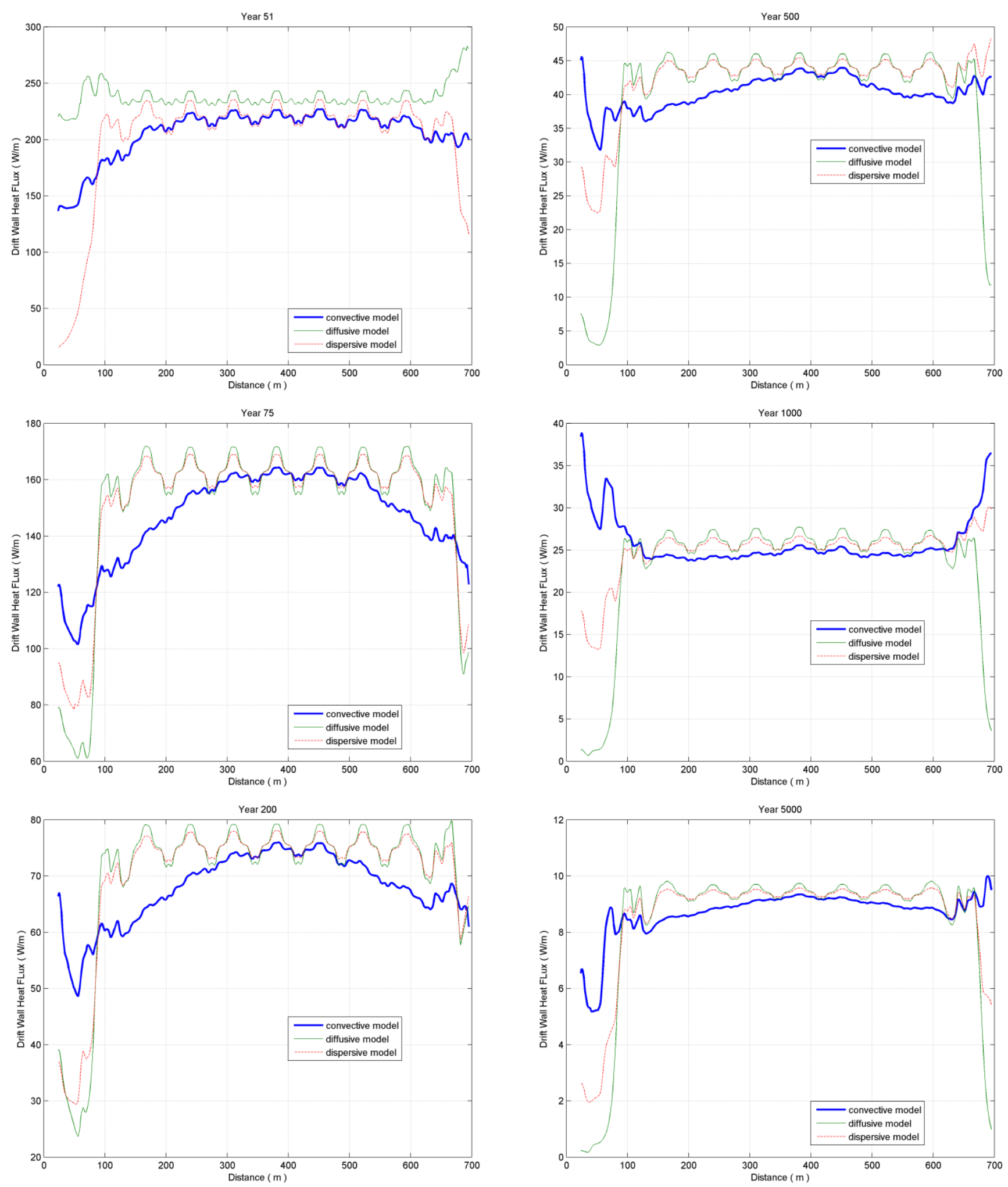

Figure 16. Drift wall heat flux distribution outside the drip shields at selected post-closure time divisions. 

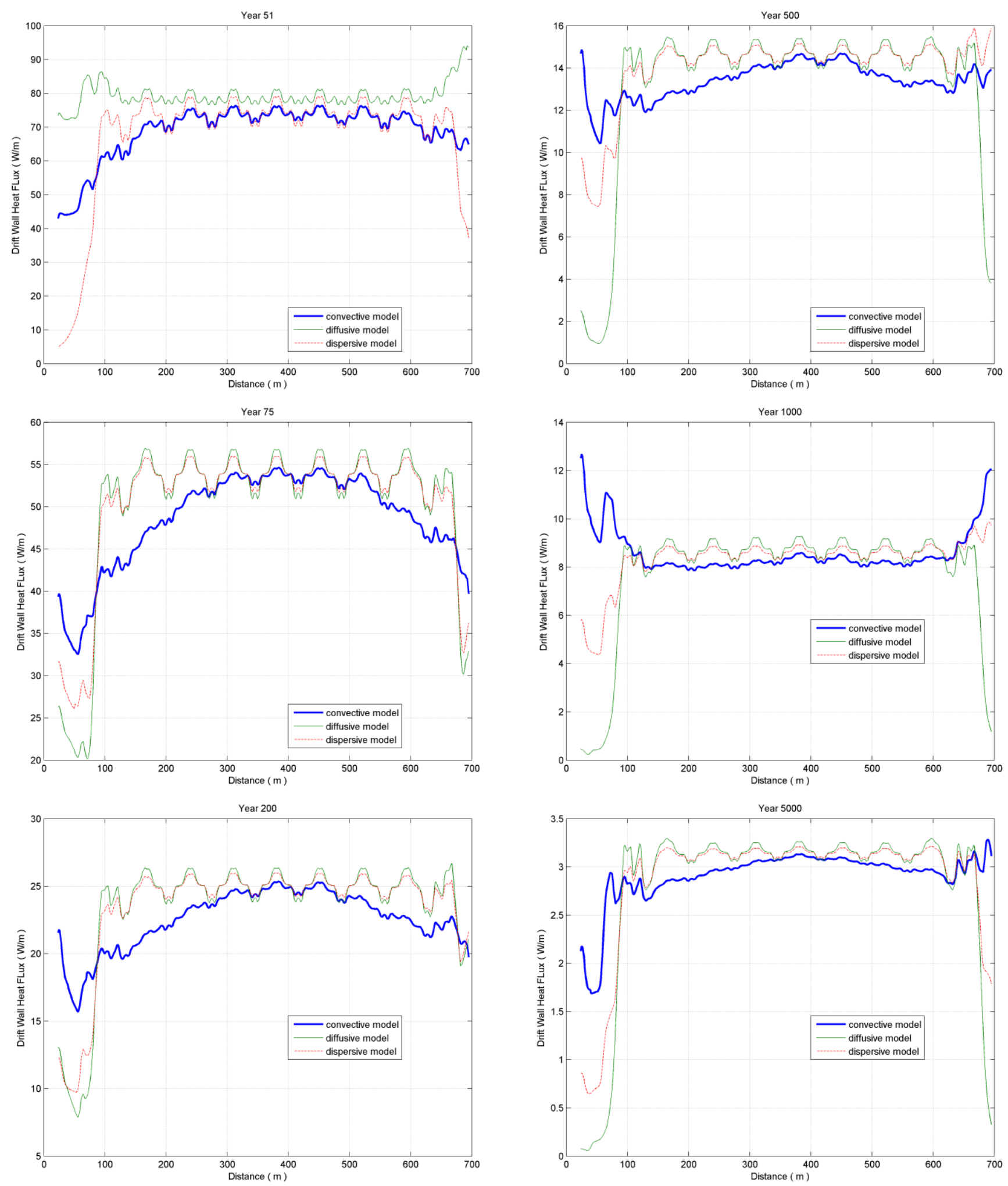

Figure 17. Drift wall heat flux distribution inside the drip shields at selected post-closure time divisions. 

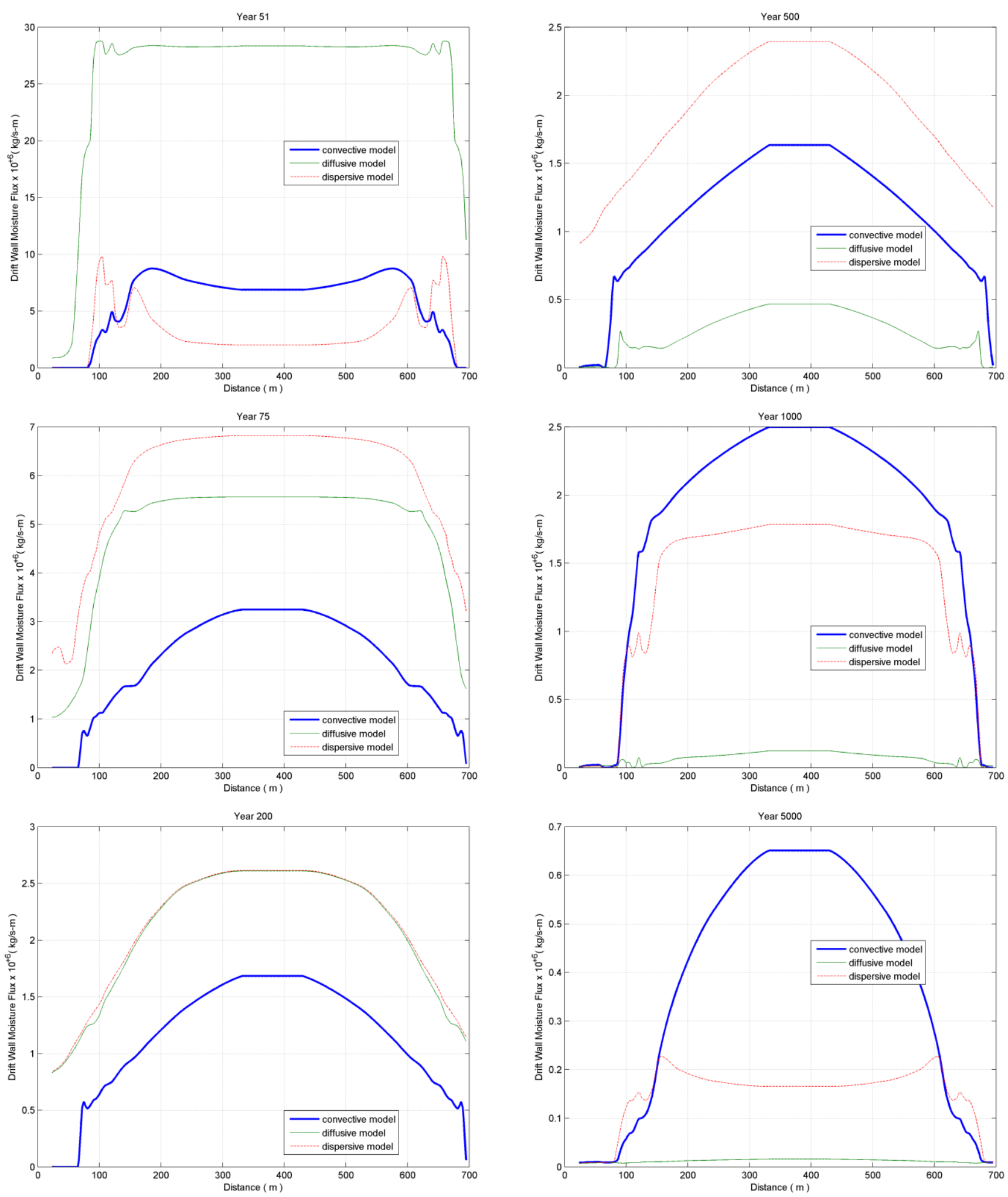

Figure 18. Drift wall moisture flux distribution outside the drip shields at selected post-closure time divisions. 

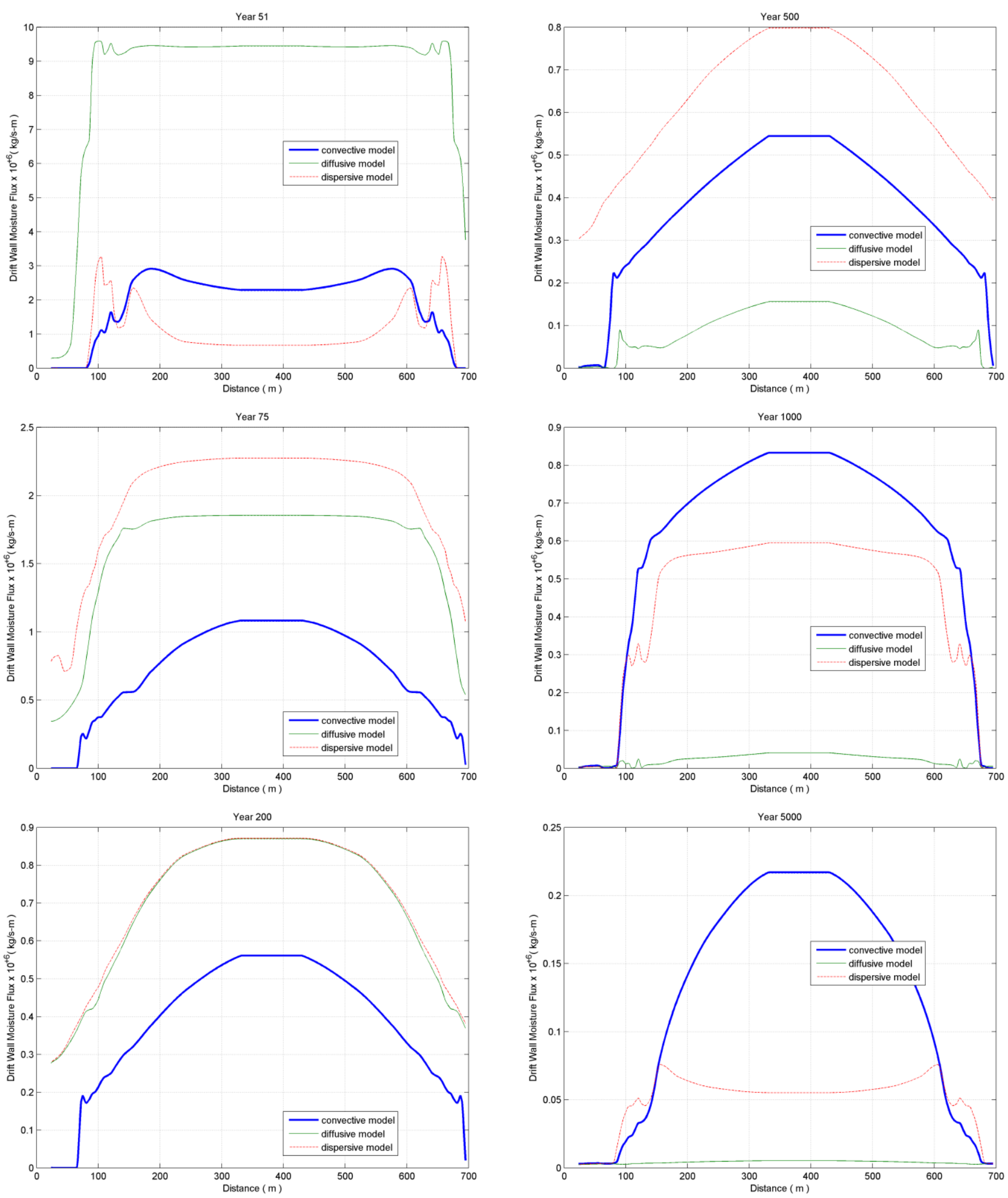

Figure 19. Drift wall moisture flux distribution inside the drip shields at selected post-closure time divisions. 


\section{FIGURE CAPTIONS}

Figure 1. In-drift and in-rock transport processes in the coupled in-drift and in-rock model.

Figure 2. Schematic diagram of the natural, axial air-recirculation loops outside (a); and inside (b) the drip shields. Transversal air flow loops in the vertical cross section outside (c); and inside (d) the drip shields are also shown.

Figure 3. MULTIFLUX solution flowchart.

Figure 4. Variable, post-closure heat load per unit length for individual WPs at year 50 (solid line).

Figure 5. Axial air velocity variation outside the drip shields at selected post-closure time divisions.

Figure 6. Axial air velocity variation inside the drip shields at selected post-closure time divisions.

Figure 7. Transversal air velocity variation outside the drip shields at selected post-closure time divisions.

Figure 8. Transversal air velocity variation inside the drip shields at selected post-closure time divisions.

Figure 9. Drift wall temperature distribution in the airspace outside the drip shields at selected post-closure time divisions.

Figure 10. Drift invert temperature distribution in the airspace inside the drip shields at selected post-closure time divisions.

Figure 11. Drift wall relative humidity distribution in the airspace outside the drip shields at selected post-closure time divisions.

Figure 12. Drift invert relative humidity distribution in the airspace inside the drip shields at selected post-closure time divisions. 
Figure 13. Condensation rate distribution outside the drip shields at selected post-closure time divisions.

Figure 14. Condensation rate distribution inside the drip shields at selected post-closure time divisions.

Figure 15. The evolution of total condensation rate (solid line) and vapor inflow rate (dashed line) in the emplacement drift.

Figure 16. Drift wall moisture flux distribution outside the drip shields at selected post-closure time divisions.

Figure 17. Drift wall moisture flux distribution inside the drip shields at selected post-closure time divisions.

Figure 18. Drift wall heat flux distribution outside the drip shields at selected post-closure time divisions.

Figure 19. Drift wall heat flux distribution inside the drip shields at selected post-closure time divisions. 


\section{DISCLAIMER}

This document was prepared as an account of work sponsored by the United States Government. While this document is believed to contain correct information, neither the United States Government nor any agency thereof, nor The Regents of the University of California, nor any of their employees, makes any warranty, express or implied, or assumes any legal responsibility for the accuracy, completeness, or usefulness of any information, apparatus, product, or process disclosed, or represents that its use would not infringe privately owned rights. Reference herein to any specific commercial product, process, or service by its trade name, trademark, manufacturer, or otherwise, does not necessarily constitute or imply its endorsement, recommendation, or favoring by the United States Government or any agency thereof, or The Regents of the University of California. The views and opinions of authors expressed herein do not necessarily state or reflect those of the United States Government or any agency thereof or The Regents of the University of California.

Ernest Orlando Lawrence Berkeley National Laboratory is an equal opportunity employer. 